\title{
Acid/Base-Tunable Unimolecular Chirality Switching of a Pillar[5]azacrown pseudo[1]Catenane
}

Haozhong Liang, ${ }^{\dagger, \#}$ Bin Hua, ${ }^{*},{ }^{\dagger}, \#$ Fan Xu, ${ }^{\dagger}$ Li-She Gan, ${ }^{\dagger}, \S$ Li Shao ${ }^{*},{ }^{\prime}$ and Feihe Huang ${ }^{*}, \dagger, \|$

${ }^{\dagger}$ State Key Laboratory of Chemical Engineering, Center for Chemistry of High-Performance \& Novel Materials, Department of Chemistry, Zhejiang University, Hangzhou 310027, P. R. China; Fax and Tel: +86-571-8795-3189; Email: huabin@zju.edu.cn; lishao@zju.edu.cn; fhuang@zju.edu.cn.

"Green Catalysis Center and College of Chemistry, Zhengzhou University, Zhengzhou 450001, P. R. China.

*College of Pharmaceutical Sciences, Zhejiang University, Hangzhou 310058, People's Republic of China.

${ }^{\S}$ School of Biotechnology and Health Sciences, Wuyi University, Jiangmen, Guangdong 529020, People's Republic of China.

\section{Supporting Information ( 28 pages)}

1. Materials and methods $\quad$ S2

2. The investigation of host-guest complexation between 1 and DETA/TETA S3

$\begin{array}{ll}\text { 3. Synthesis of PN3 and PN4 } & \text { S7 }\end{array}$

4. X-ray crystal data for 1DDETA, PN3 and in-pS-PN4 S14

5. ${ }^{1} H$ NMR spectra of PN3 in the presence of acid $\quad$ S17

$\begin{array}{ll}\text { 6. HPLC resolution of rac-PN4 } & \text { S18 }\end{array}$

7. Quantum chemical calculation of the absolute conformations of P1 and P2 $\quad$ S20

$\begin{array}{ll}\text { 8. CD spectra of in-pS-PN4 } & \text { S24 }\end{array}$

9. X-ray crystal data for $\mathbf{P N 3 - H C l}$ and $\mathbf{P N 4 - H C l} \quad \mathrm{S} 25$

10. ${ }^{1} H$ NMR and CD spectra of PN4 in the presence of different acids S27

$\begin{array}{ll}\text { 11. References } & \text { S28 }\end{array}$ 


\section{Materials and methods}

\section{Materials}

All reagents were commercially available and used as supplied without further purification. Solvents were either employed as purchased or dried according to procedures described in the literature. Compound $\mathbf{1}$ was synthesized according to previous literature. ${ }^{\mathrm{S} 1}$

\section{Methods}

NMR spectra were recorded with a Bruker Avance DMX 600 spectrometer or a Bruker Avance DMX 500 spectrometer with the deuterated solvent as the lock and the residual solvent or TMS as the internal reference. 2D NOESY NMR spectra were collected on a Bruker Avance DMX-500 spectrometer with internal standard TMS. GC-TOF mass spectra were obtained on an IonSpec 4.7 Tesla FTMS mass spectrometry instrument. The crystal data were collected on an Oxford Diffraction Xcalibur Atlas Gemini Ultra instrument. Chiral HPLC was performed on a Shimadzu LC-20AT, CP-HPLC-07 instrument (CHIRALPAK ID: ID00CD-TB002) with column size of $0.46 \mathrm{~cm}$ I.D. $\times 15 \mathrm{~cm} \mathrm{~L}(\mathrm{MeOH} / \mathrm{DCM} / \mathrm{DEA}=70 / 30 / 0.1, v / v / v, 1.0$ $\mathrm{mL} / \mathrm{min}$ ). Circular dichroism spectra (CD) were measured on a JASCO J-1500 spectrometer using a quartz cuvette of $1 \mathrm{~cm}$ path length installed in a Unisoku cryostat. The fluorescence experiments were conducted on a RF-5301 spectrofluorimeter (Shimadzu Corporation, Japan). 


\section{The investigation of host-guest complexation between 1 and DETA/TETA}

To determine the stoichiometries and association constants for the complexation between 1 and guests G (DETA/TETA), fluorescence titration experiments ( $\lambda_{e x}=280$ $\mathrm{nm})$ were done with solutions which had a constant concentration of $\mathbf{1}\left(1.00 \times 10^{-3} \mathrm{M}\right)$ and varying concentrations of $\mathbf{G}$. By a non-linear curve-fitting method, the association constants $\left(K_{\mathrm{a}}\right)$ of $\mathbf{1} \supset \mathbf{G}$ were determined. By a mole ratio plot, 1:1 stoichiometry was obtained for the complexation between $\mathbf{1}$ and $\mathbf{G}$.

The non-linear curve-fittings were based on the equation:

$\Delta F=\left(\Delta F_{\infty} /[\mathbf{1}]_{0}\right)\left(0.5[\mathbf{G}]_{0}+0.5\left([\mathbf{1}]_{0}+1 / K_{\mathrm{a}}\right)-\left(0.5\left([\mathbf{G}]_{0}^{2}+\left(2[\mathbf{G}]_{0}\left(1 / K_{\mathrm{a}}-[\mathbf{1}]_{0}\right)\right)+\left(1 / K_{\mathrm{a}}+\right.\right.\right.\right.$ $\left.\left.\left.\left.[\mathbf{1}]_{0}\right)^{2}\right)^{0.5}\right)\right)($ Eq. S1)

where $\Delta F$ is the fluorescence intensity change at $330 \mathrm{~nm}$ at $[\mathbf{G}]_{0}, \Delta F_{\infty}$ is the fluorescence intensity change at $330 \mathrm{~nm}$ when $\mathbf{1}$ is completely complexed, [G] $]_{0}$ is the initial concentration of $\mathbf{G}$, and $[\mathbf{1}]_{0}$ is the fixed initial concentration of $\mathbf{1}$.

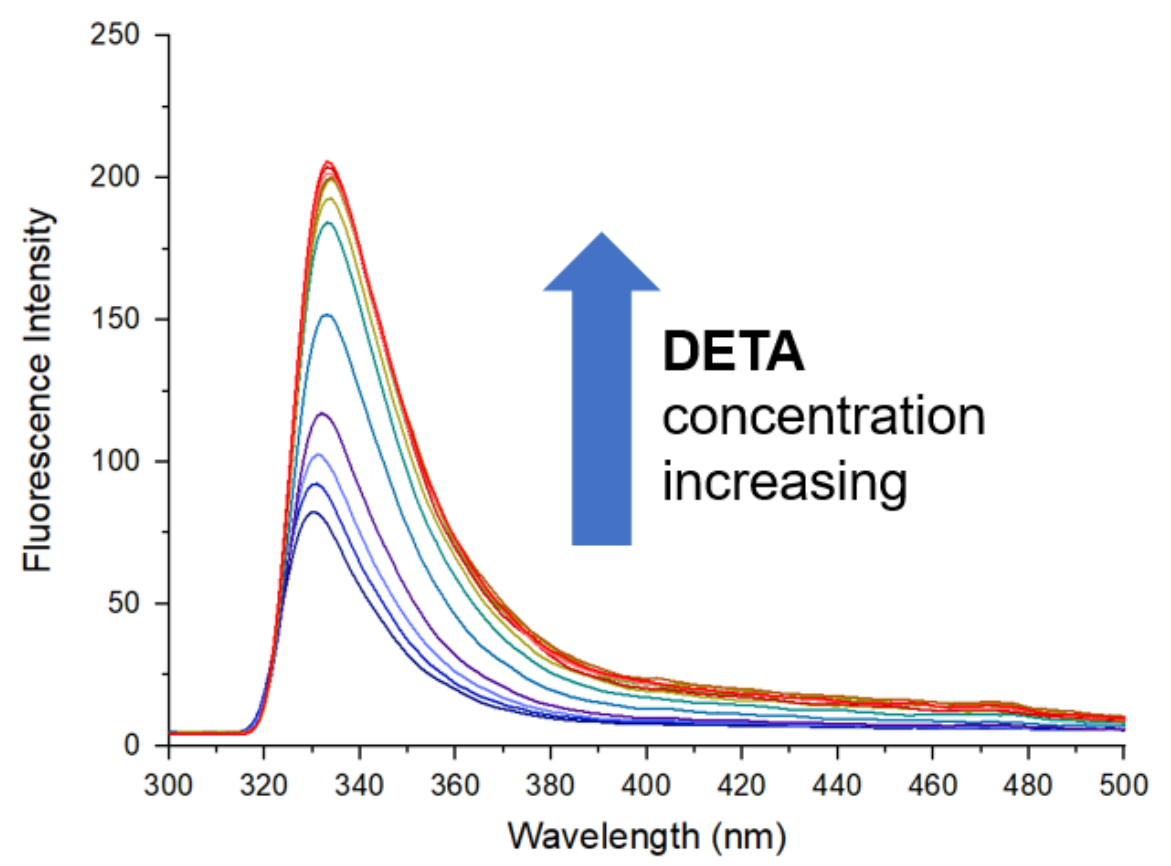

Figure S1. Fluorescence spectra $\left(\lambda_{\mathrm{ex}}=280 \mathrm{~nm}\right)$ of $\mathbf{1}$ at a concentration of $1.00 \times 10^{-3}$ $M$ in THF solution at room temperature upon different concentrations of DETA: 0, $1.00 \times 10^{-4}, 3.00 \times 10^{-4}, 6.00 \times 10^{-4}, 1.00 \times 10^{-3}, 1.50 \times 10^{-3}, 2.00 \times 10^{-3}, 3.00 \times 10^{-3}$, $4.00 \times 10^{-3}, 5.00 \times 10^{-3}, 6.00 \times 10^{-3}, 8.00 \times 10^{-3}$ and $1.00 \times 10^{-2} \mathrm{M}$. 


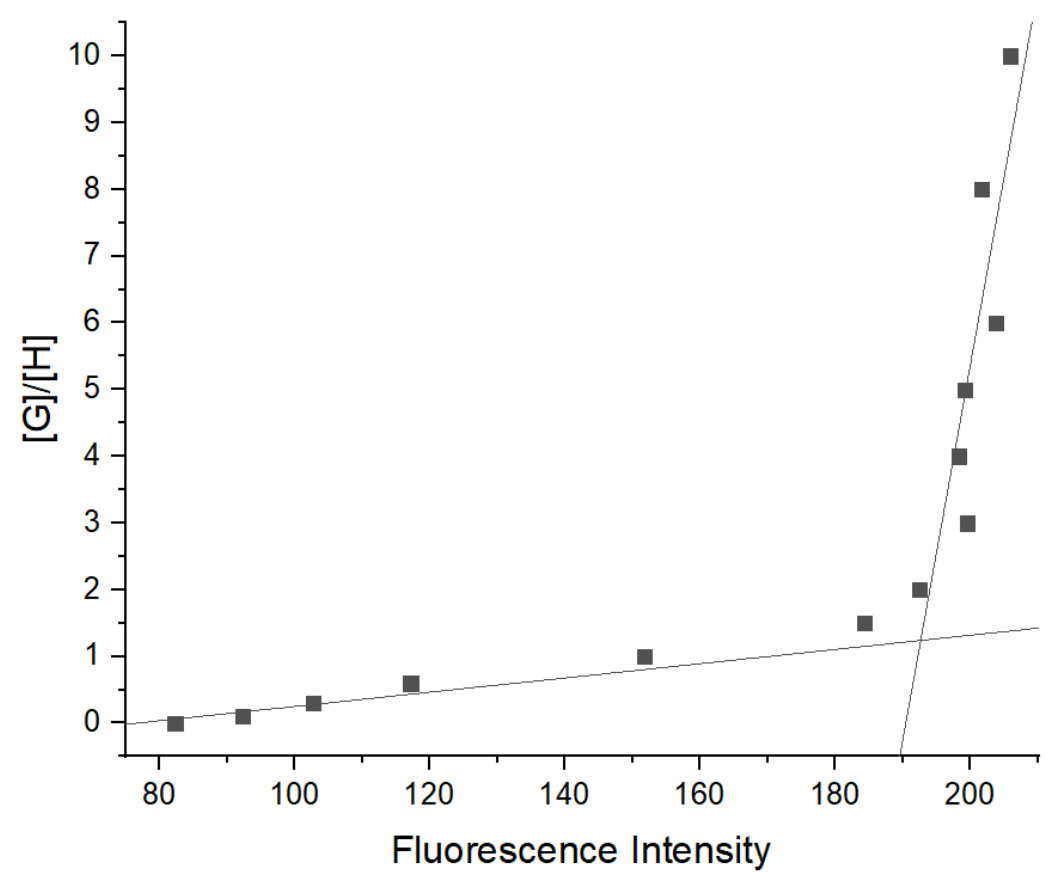

Figure S2. Mole ratio plot for $\mathbf{1}$ and DETA, showing a 1:1 complexation stoichiometry.

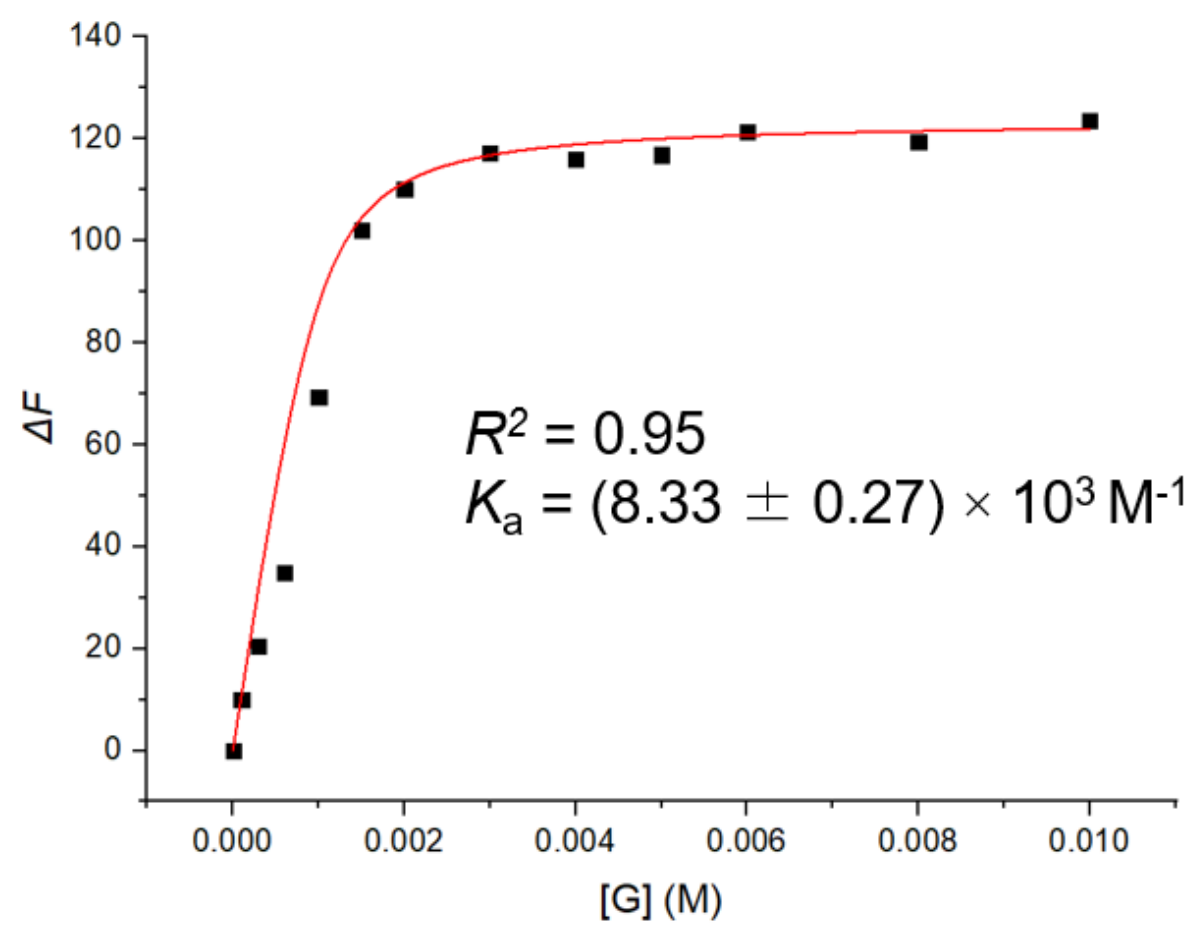

Figure S3. The fluorescence intensity changes of 1 upon addition of DETA. The red solid line was obtained from the non-linear curve-fitting method based on the above equation. 
(a)

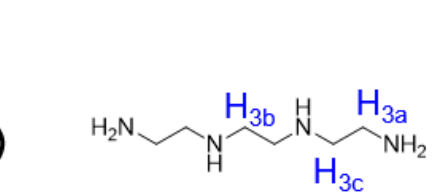

(b)

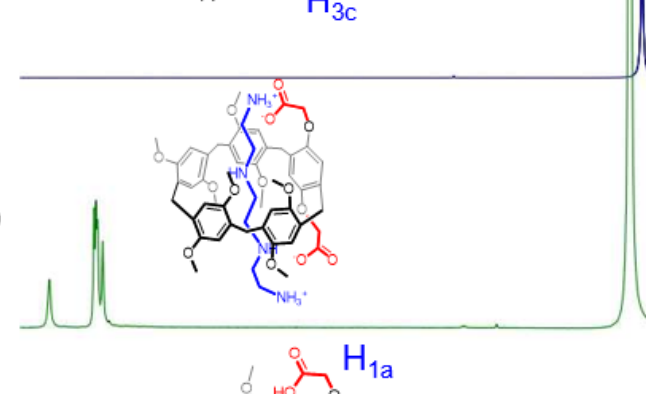

(c)

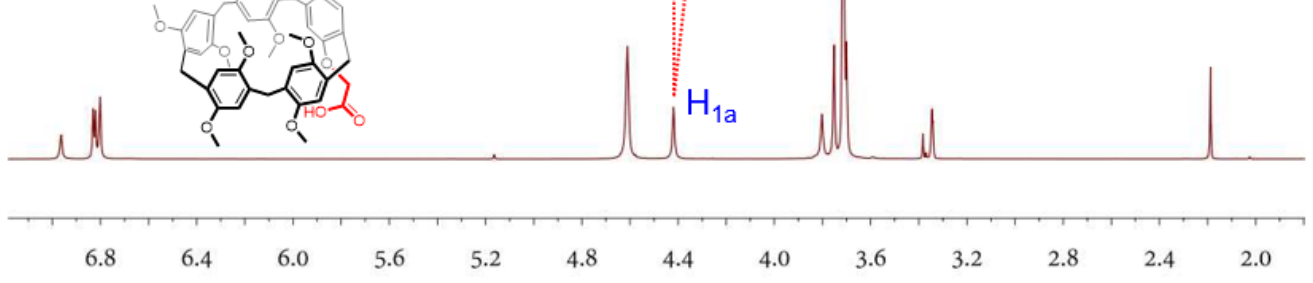

Figure S4. Partial ${ }^{1} \mathrm{H}$ NMR spectra $\left(500 \mathrm{MHz}, \mathrm{CDCl}_{3}: \mathrm{CD}_{3} \mathrm{OD}=1: 1,298 \mathrm{~K}\right)$ : (a) TETA; (b) a mixture of $1.00 \mathrm{mM}$ TETA and $1.14 \mathrm{mM} \mathrm{1;} \mathrm{(c)} 1$.

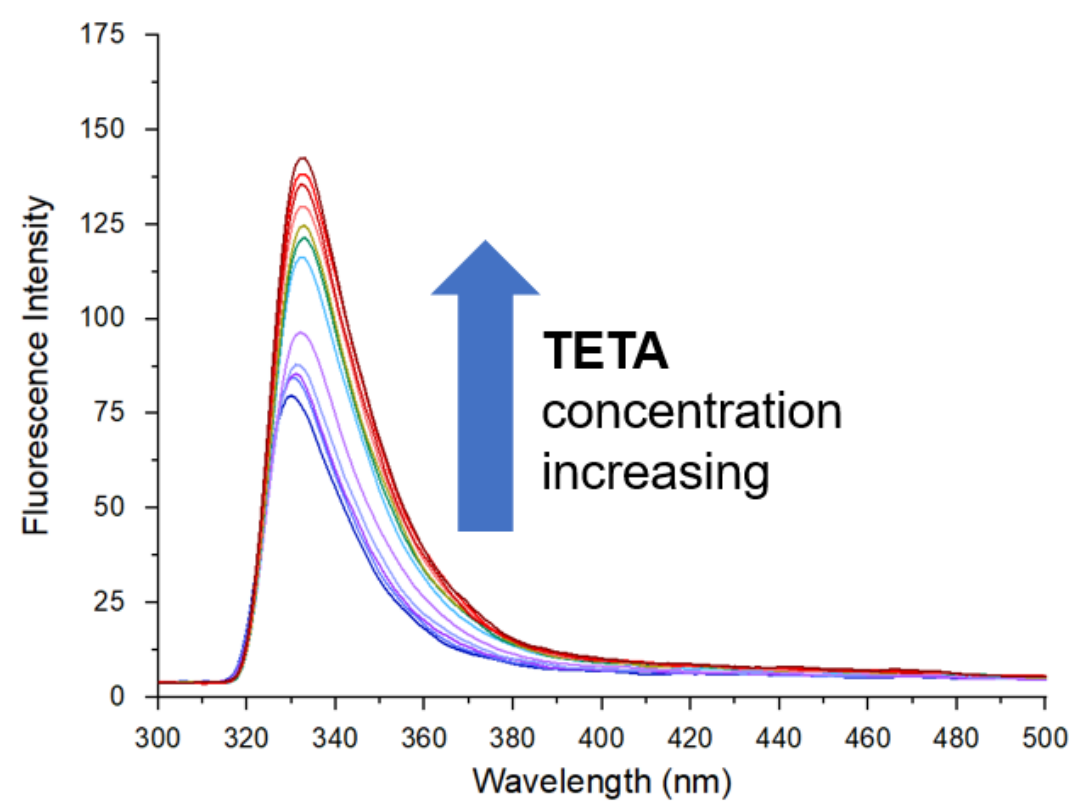

Figure S5. Fluorescence spectra $\left(\lambda_{\mathrm{ex}}=280 \mathrm{~nm}\right)$ of $\mathbf{1}$ at a concentration of $1.00 \times 10^{-3}$ $\mathrm{M}$ in THF solution at room temperature upon different concentrations of TETA: 0, $1.00 \times 10^{-4}, 2.00 \times 10^{-4}, 4.00 \times 10^{-4}, 6.00 \times 10^{-4}, 8.00 \times 10^{-4}, 1.50 \times 10^{-3}, 2.00 \times 10^{-3}$, $4.00 \times 10^{-3}, 6.50 \times 10^{-3}, 8.00 \times 10^{-3}$ and $1.00 \times 10^{-2} \mathrm{M}$. 


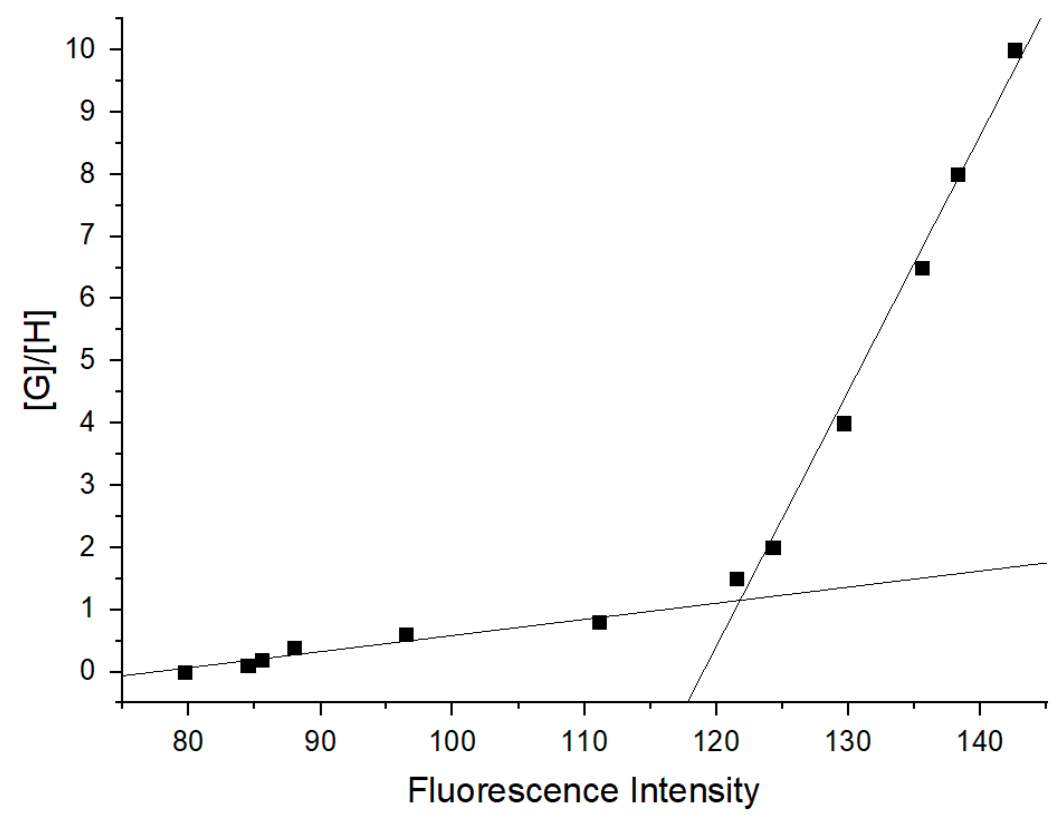

Figure S6. Mole ratio plot for $\mathbf{1}$ and TETA, showing a 1:1 complexation stoichiometry.

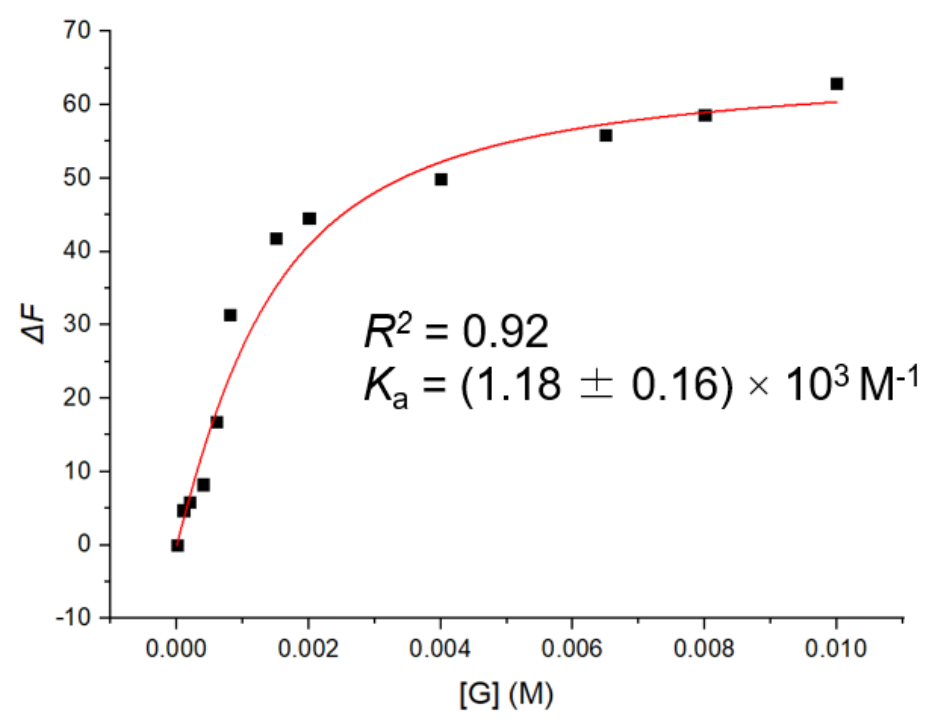

Figure S7. The fluorescence intensity changes of $\mathbf{1}$ upon addition of TETA. The red solid line was obtained from the non-linear curve-fitting method based on the above equation. 


\section{Synthesis of PN3 and PN4}

PN3 and PN4 were synthesized by the following methods: ${ }^{\mathrm{S} 2}$

PN3: $838 \mathrm{mg}(1.00 \mathrm{mmol})$ of $\mathbf{1}$ were dissolved in chloroform $(100 \mathrm{~mL})$ and stirred at room temperature and then HOBt $(202 \mathrm{mg}, 1.50 \mathrm{mmol})$ and EDC (288 $\mathrm{mg}$, $1.50 \mathrm{mmol}$ ) were added. DETA (103 $\mathrm{mg}, 1.00 \mathrm{mmol})$ was dissolved in chloroform $(10 \mathrm{~mL})$ and the resultant solution was added dropwise into the solution of $\mathbf{1}$. After reaction for $48 \mathrm{~h}$ at room temperature, the mixture was washed with water and brine, dried over $\mathrm{Na}_{2} \mathrm{SO}_{4}$, and concentrated. The residue was purified by chromatography on silica gel $\left(\mathrm{CH}_{2} \mathrm{Cl}_{2}: \mathrm{MeOH}, 10: 1\right.$ to $\left.4: 1 \mathrm{v}: v\right)$. The product $(360 \mathrm{mg}, 40 \%)$ was a white solid, mp: over $300{ }^{\circ} \mathrm{C}$. The ${ }^{1} \mathrm{H}$ NMR spectrum of compound PN3 is shown in Figure S4. ${ }^{1} \mathrm{H}$ NMR (500 MHz, $\left.\mathrm{CDCl}_{3}, 298 \mathrm{~K}\right) \delta$ (ppm): 7.08 (s, 2H), 6.91 (s, 2H), 6.89 (s, 2H), 6.85 (s, 2H), $6.82(\mathrm{~s}, 2 \mathrm{H}), 4.95-4.93(\mathrm{t}, 2 \mathrm{H}, J=5 \mathrm{~Hz}), 4.86-4.63(\mathrm{dd}, 4 \mathrm{H}, J=5$ $\mathrm{Hz}), 3.79$ (s, 2H), 3.76-3.75 (m, 20H), 3.71-3.69 (d, 12H, J = 4 Hz), 2.38-2.33 (m, 2H), $1.99-1.93(\mathrm{~m}, 2 \mathrm{H}), 0.10-0.07(\mathrm{~m}, 2 \mathrm{H}),-0.17$ to $-0.02(\mathrm{~m}, 2 \mathrm{H})$. The ${ }^{13} \mathrm{C}$ NMR spectrum of PN3 is shown in Figure S5. ${ }^{13} \mathrm{C} \mathrm{NMR}\left(500 \mathrm{MHz}, \mathrm{CDCl}_{3}, 298 \mathrm{~K}\right) \delta$ (ppm): 167.46, 150.67, 150.32, 150.18, 149.59, 147.05, 128.94, 128.20, 127.22, $114.13,113.20,113.09,112.93,77.23,77.02$, 76.81, 65.87, 55.48, 55.46, 55.45, 55.42, $46.43,38.19,29.37,28.98,28.75$. The GC-TOF mass spectrum is shown in Figure S7: $m / z$ calcd for $[\mathbf{P N 3}+\mathrm{H}]^{+} \mathrm{C}_{51} \mathrm{H}_{60} \mathrm{~N}_{3} \mathrm{O}_{12}{ }^{+}, 906.4172$; found 906.4172 , error 0 ppm. 


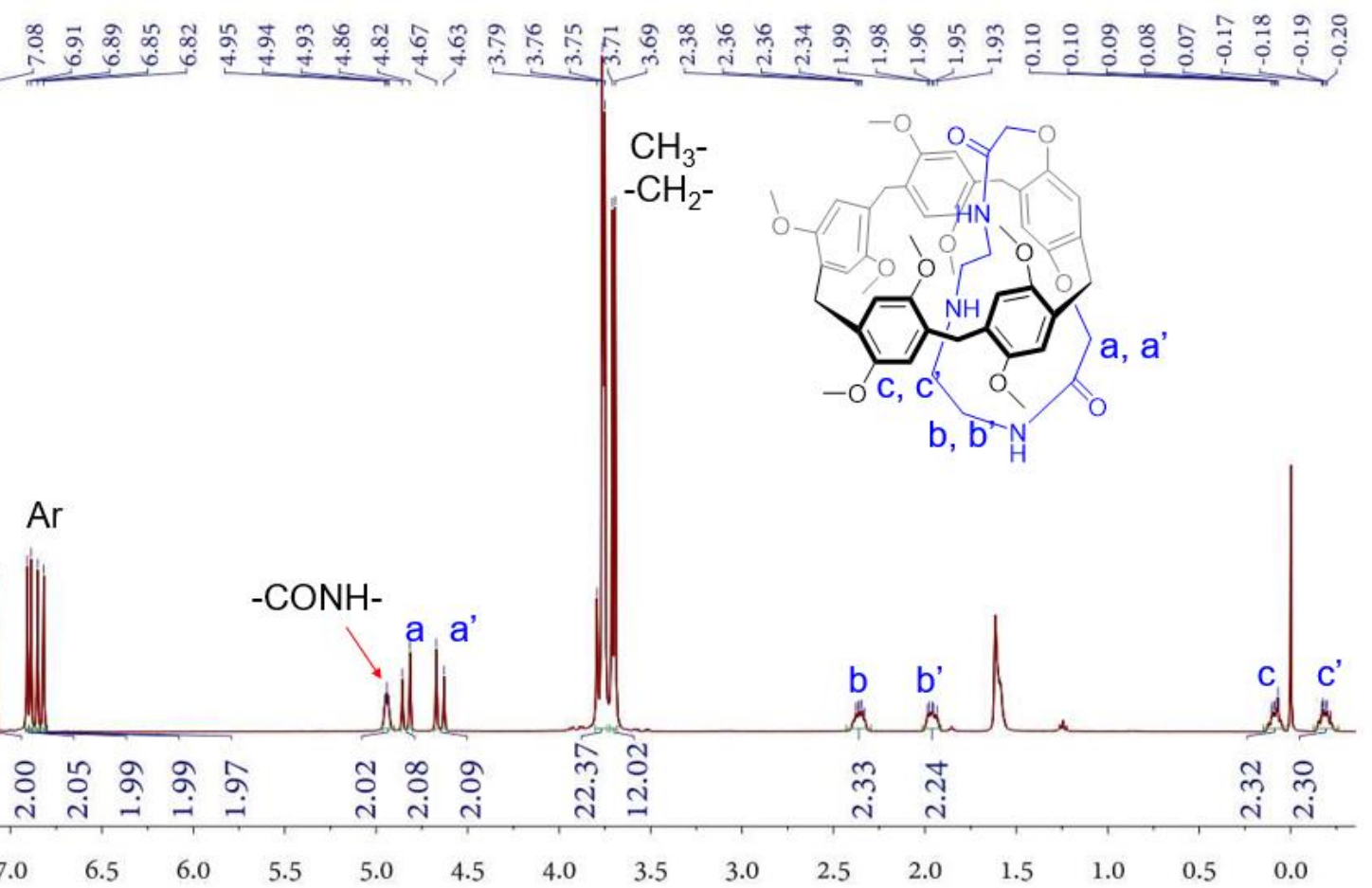

Figure S8. ${ }^{1} \mathrm{H}$ NMR spectrum of $\mathbf{P N 3}\left(500 \mathrm{MHz}, \mathrm{CDCl}_{3}, 298 \mathrm{~K}\right)$.

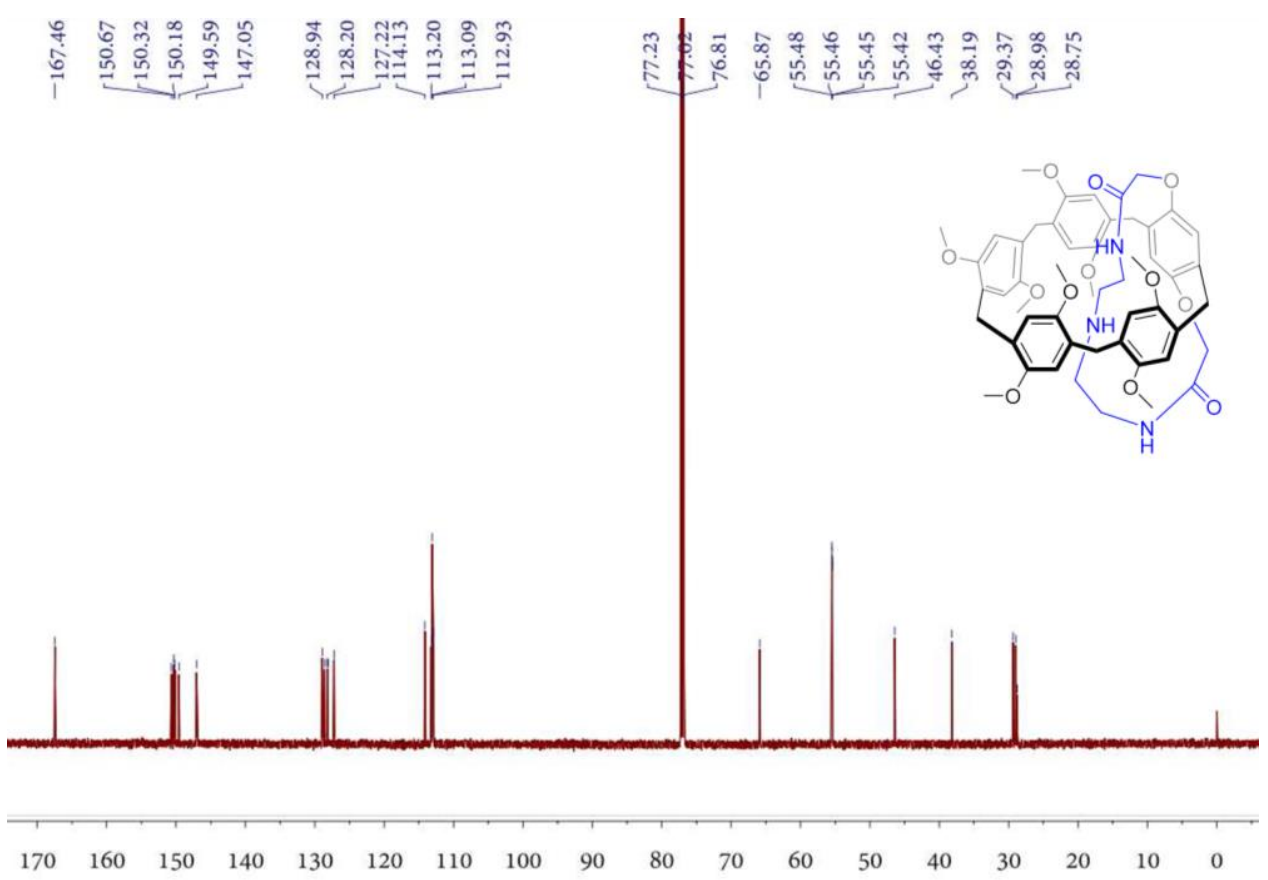

Figure S9. ${ }^{13} \mathrm{C}$ NMR spectrum of PN3 (125 MHz, $\mathrm{CDCl}_{3}, 298 \mathrm{~K}$ ). 


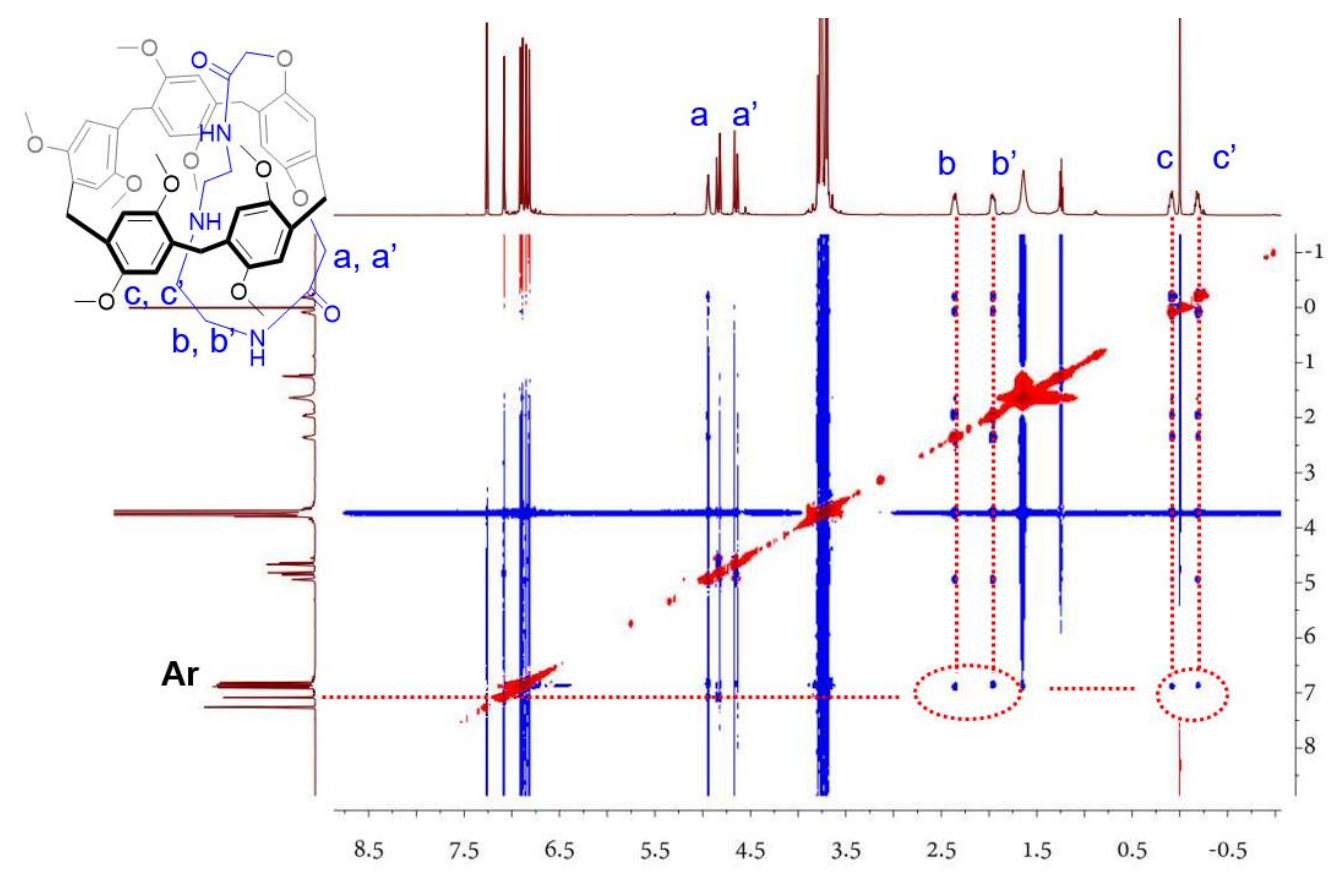

Figure S10. Partial 2D NOESY NMR spectrum of PN3 (500 MHz, CDCl 3 , $298 \mathrm{~K})$.

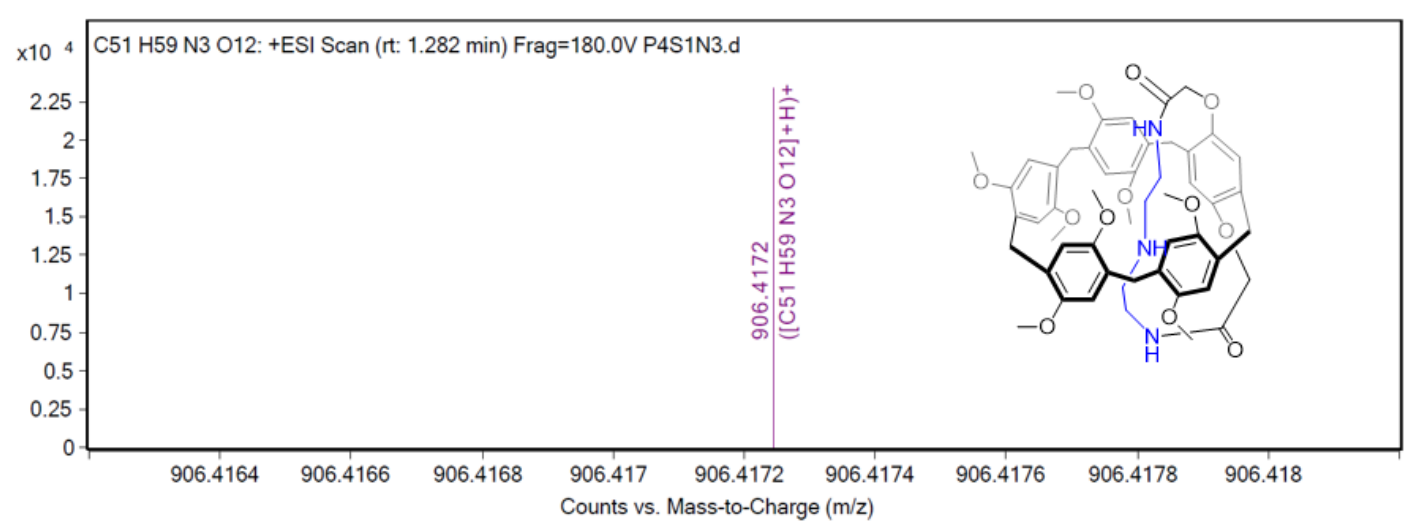

Figure S11. GC-TOF mass spectrum of PN3. Assignment of the main peak: $\mathrm{m} / \mathrm{z}$ $906.4172[\mathbf{P N 3}+\mathrm{H}]^{+}$. 
PN4: $838 \mathrm{mg}$ (1.00 mmol) of $\mathbf{1}$ was dissolved in chloroform $(100 \mathrm{~mL})$ and stirred at room temperature and then $\mathrm{HOBt}(202 \mathrm{mg}, 1.50 \mathrm{mmol})$ and EDC (288 mg, $1.50 \mathrm{mmol})$ were added into the solution. TETA (146 mg, $1.00 \mathrm{mmol})$ was dissolved in chloroform $(10 \mathrm{~mL})$ and the solution was added dropwise. After reaction for $48 \mathrm{~h}$ at room temperature, the mixture was washed with water and brine, dried over $\mathrm{Na}_{2} \mathrm{SO}_{4}$, and concentrated. The residue was purified by chromatography on silica gel $\left(\mathrm{CH}_{2} \mathrm{Cl}_{2}: \mathrm{MeOH}, 10: 1\right.$ to $\left.4: 1 v: v\right)$. The product (270 mg, 28\%) was a white solid, mp: 253.5-254.3 ${ }^{\circ} \mathrm{C}$. The ${ }^{1} \mathrm{H}$ NMR spectrum of PN4 is shown in Figure S8. ${ }^{1} \mathrm{H}$ NMR (500 $\left.\mathrm{MHz}, \mathrm{CDCl}_{3}, 298 \mathrm{~K}\right) \delta$ (ppm): 6.91-6.88 (m, 10H), 6.76 (s, 2H), 4.73-4.46 (dd, 4H, $J$ $=5 \mathrm{~Hz}), 3.77-3.74(\mathrm{~m}, 34 \mathrm{H}), 2.96(\mathrm{~s}, 2 \mathrm{H}), 2.76(\mathrm{~s}, 2 \mathrm{H}), 2.05(\mathrm{~s}, 2 \mathrm{H}), 1.51(\mathrm{~s}, 2 \mathrm{H})$, -0.53 (s, 2H), -0.78 (s, 2H). The ${ }^{13} \mathrm{C}$ NMR spectrum of PN4 is shown in Figure S9. ${ }^{13} \mathrm{C}$ NMR (500 MHz, $\left.\mathrm{CDCl}_{3}, 298 \mathrm{~K}\right) \delta$ (ppm): 167.61, 149.57, 149.45, 149.26, 149.22, $147.14,127.69$, 127.34, 127.13, 126.98, 112.60, 112.51, 112.17, 111.92, 111.71, 76.27, 76.01, 75.76, 66.05, 55.25, 54.43, 54.31, 44.89, 44.57, 35.41, 28.08, 27.83. GC-TOF mass spectrum is shown in Figure S11: $\mathrm{m} / \mathrm{z}$ calcd for $[\mathbf{P N} 4+\mathrm{H}]^{+}$ $\mathrm{C}_{53} \mathrm{H}_{65} \mathrm{~N}_{4} \mathrm{O}_{12}{ }^{+}$, 949.4593; found 949.4594, error $0.1 \mathrm{ppm}$.

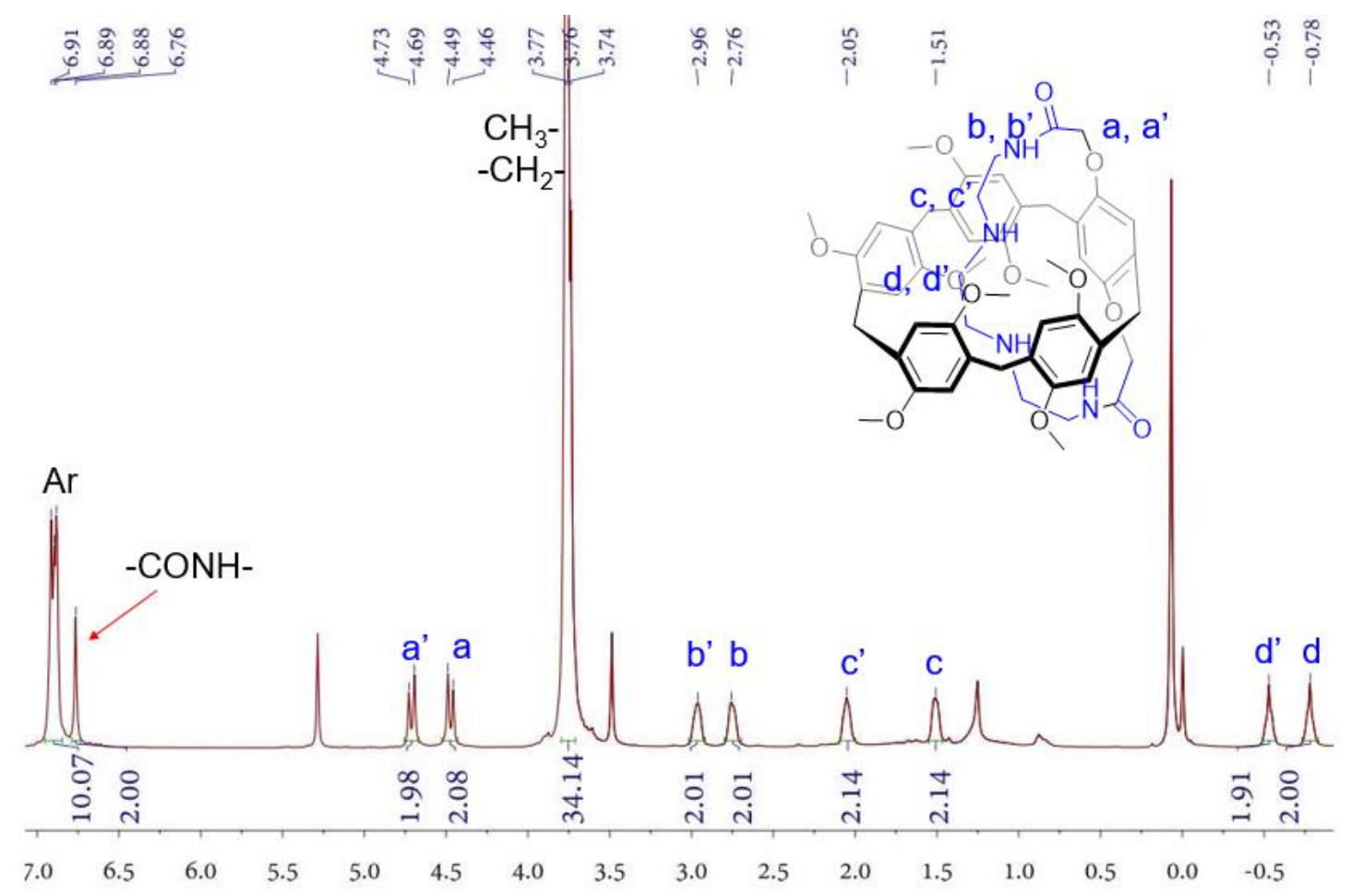

Figure S12 ${ }^{1} \mathrm{H}$ NMR spectrum of PN4 $\left(500 \mathrm{MHz}, \mathrm{CDCl}_{3}, 298 \mathrm{~K}\right)$. 


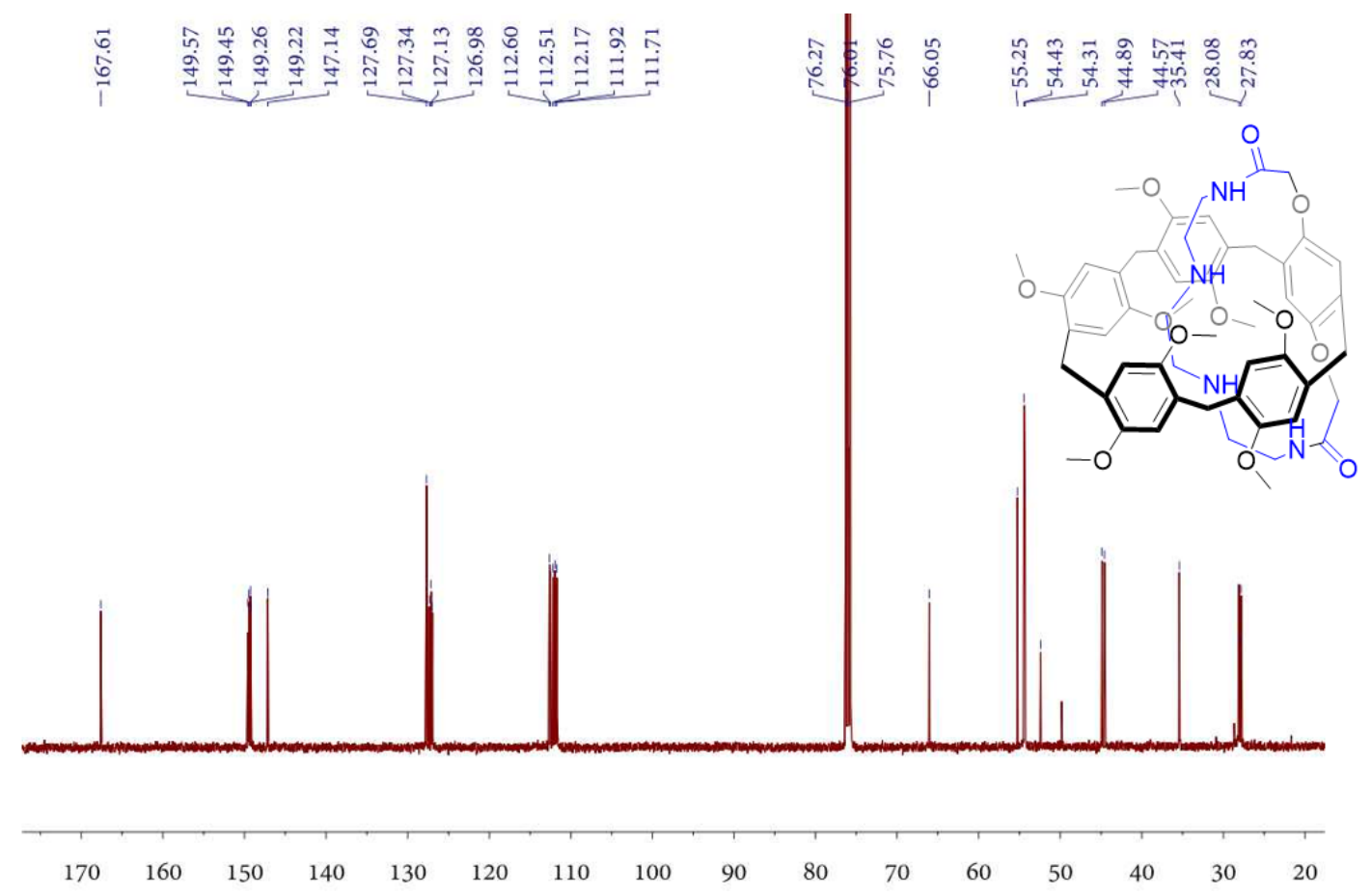

Figure S13. ${ }^{13} \mathrm{C}$ NMR spectrum of PN4 (125 MHz, $\left.\mathrm{CDCl}_{3}, 298 \mathrm{~K}\right)$.

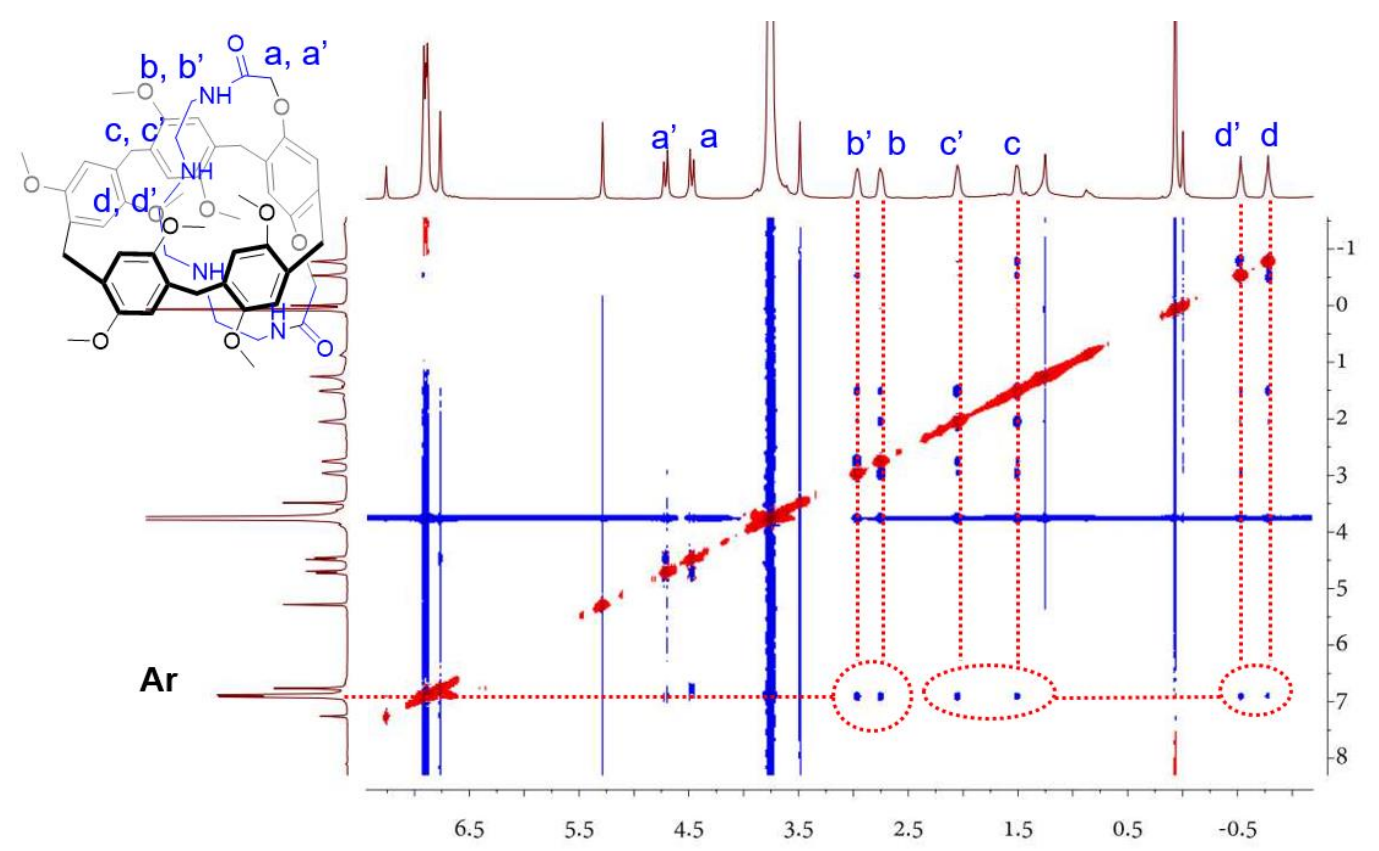

Figure S14. Partial NOESY NMR spectrum of PN4 (500 MHz, CDCl 3 , $298 \mathrm{~K}$ ). 


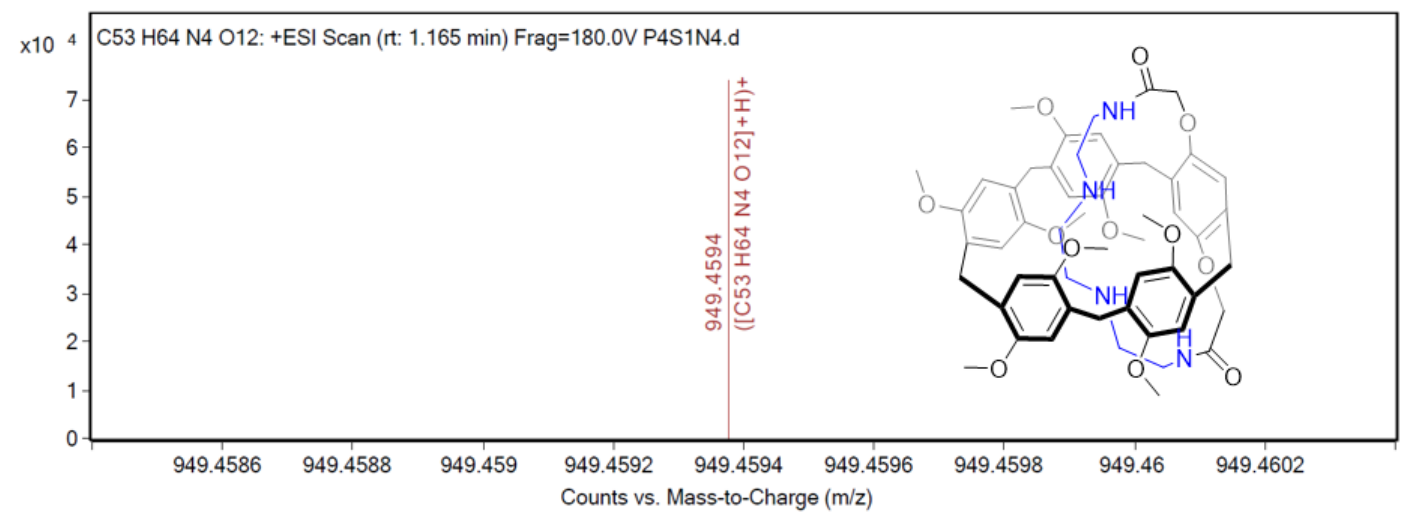

Figure S15. GC-TOF mass spectrum of PN4. Assignment of the main peak: $\mathrm{m} / \mathrm{z}$ $949.4594[\mathbf{P N} 4+\mathrm{H}]^{+}$.

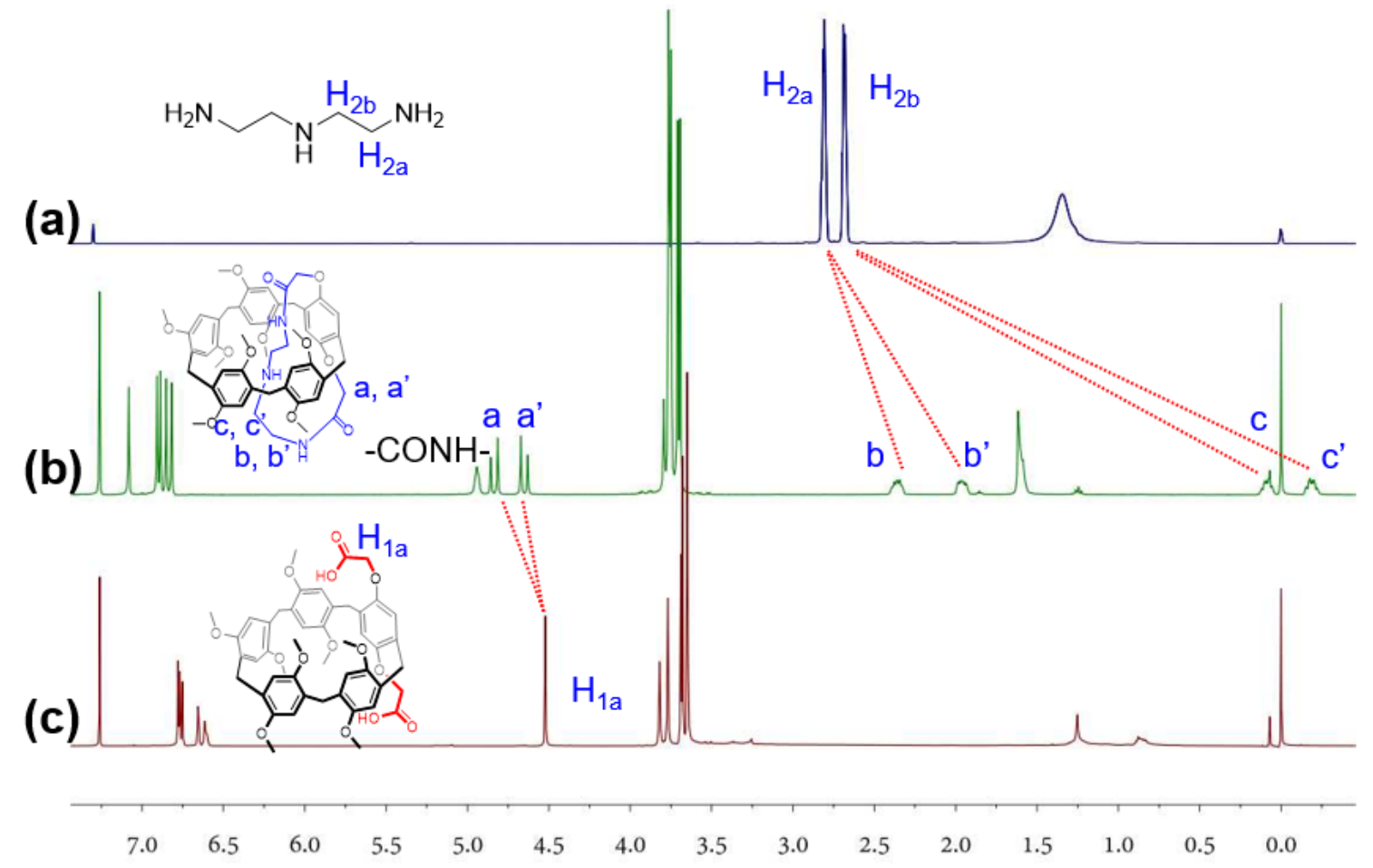

Figure S16 ${ }^{1} \mathrm{H}$ NMR spectra (500 MHz, $\left.\mathrm{CDCl}_{3}, 298 \mathrm{~K}\right)$ : (a) DETA; (b) PN3; (c) 1. 


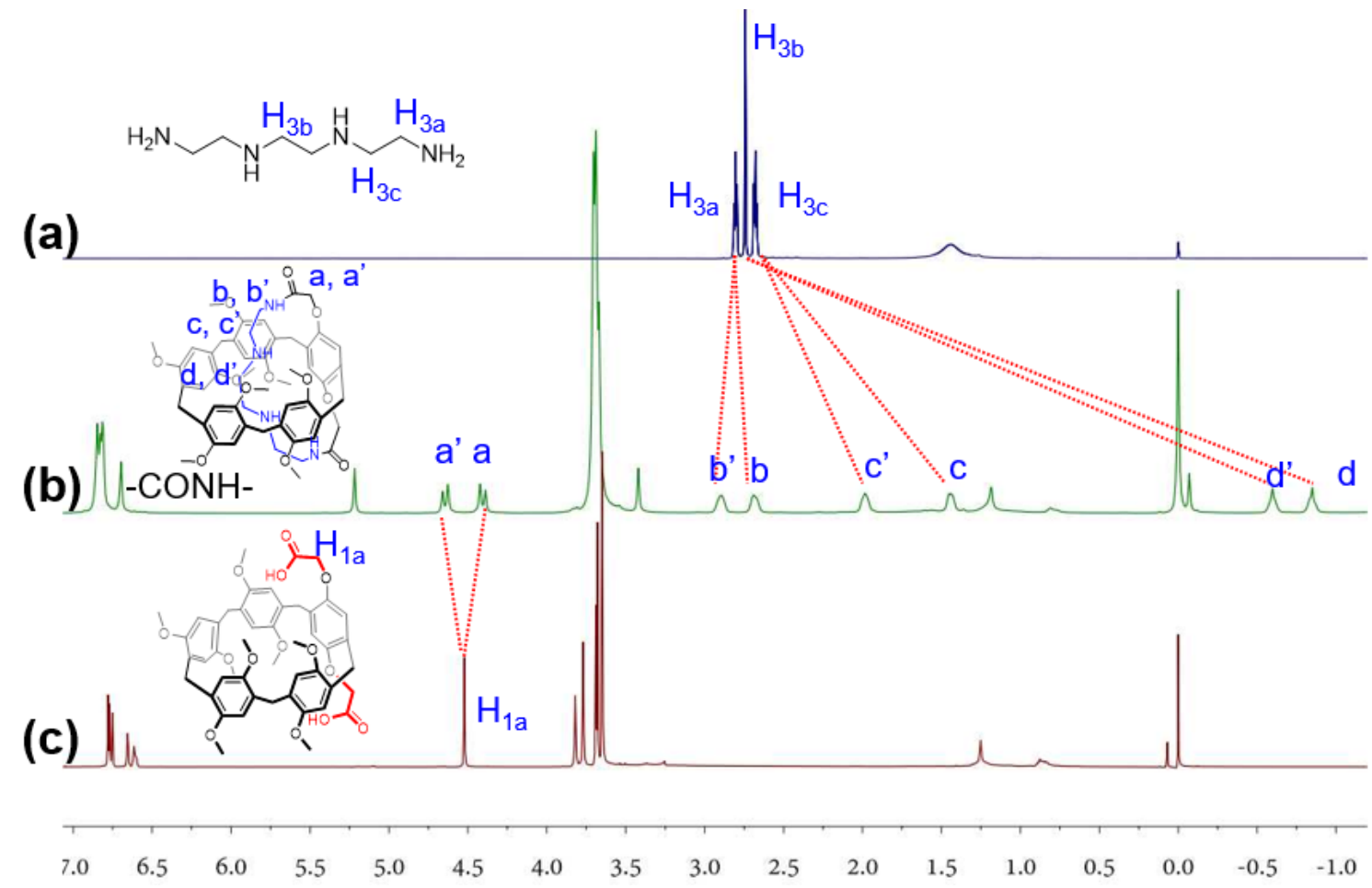

Figure $\mathbf{S 1 7}{ }^{1} \mathrm{H}$ NMR spectra (500 MHz, CDCl 3 , $\left.298 \mathrm{~K}\right)$ : (a) TETA; (b) PN4; (c) 1. 
4. X-ray crystal data for 1 DETA, PN3 and in-pS-PN4

\begin{tabular}{|c|c|c|c|}
\hline & 1つDETA & PN3 & $i n-p S-\mathbf{P N 4}$ \\
\hline Crystallization Solvent & $\mathrm{CHCl}_{3} / \mathrm{CH}_{3} \mathrm{OH}$ & $\mathrm{CHCl}_{3}$ & $\mathrm{CH}_{3} \mathrm{OH}$ \\
\hline Collection Temperature & $170.0 \mathrm{~K}$ & $170.15 \mathrm{~K}$ & $170.15 \mathrm{~K}$ \\
\hline Sum Formula & $\mathrm{C}_{53} \mathrm{H}_{71} \mathrm{~N}_{3} \mathrm{O}_{16}$ & $\mathrm{C}_{54} \mathrm{H}_{62} \mathrm{Cl}_{9} \mathrm{~N}_{3} \mathrm{O}_{12}$ & $\mathrm{C}_{56} \mathrm{H}_{76} \mathrm{~N}_{4} \mathrm{O}_{15}$ \\
\hline$M r$ & 1006.12 & 1264.11 & 1045.20 \\
\hline Crystal Size [mm] & $0.49 \times 0.16 \times 0.13$ & $0.29 \times 0.19 \times 0.1$ & $0.39 \times 0.07 \times 0.06$ \\
\hline Crystal System & Monoclinic & Orthorhombic & Orthorhombic \\
\hline Space Group & $\mathrm{C} 2 / \mathrm{c}$ & Pbca & $\mathrm{P} 2{ }_{1}{ }_{1} 2_{1}$ \\
\hline$a[\AA]$ & $20.2673(6)$ & $12.452(3)$ & $12.0165(5)$ \\
\hline$b[\AA]$ & $12.7006(4)$ & $26.389(7)$ & $18.2080(8)$ \\
\hline$c[\AA]$ & $20.9446(6)$ & $36.476(9)$ & $25.1259(11)$ \\
\hline$\alpha\left[^{\circ}\right]$ & 90 & 90 & 90 \\
\hline$\beta\left[^{\circ}\right]$ & $108.1960(10)$ & 90 & 90 \\
\hline$\gamma\left[{ }^{\circ}\right]$ & 90 & 90 & 90 \\
\hline$V[\AA 3]$ & $5121.7(3)$ & $11986(5)$ & $5497.5(4)$ \\
\hline$Z$ & 4 & 8 & 4 \\
\hline Dcalcd $[\mathrm{g} \mathrm{cm}-3]$ & 1.305 & 1.401 & 1.263 \\
\hline$\mu[\mathrm{mm}-1]$ & 0.096 & 0.481 & 0.752 \\
\hline $\mathrm{F}(000)$ & 2152.0 & 5248.0 & 2240.0 \\
\hline $2 \theta$ range $\left[{ }^{\circ}\right]$ & $4.654-54.226$ & $4.25-50.714$ & $5.994-137.092$ \\
\hline Reflections collected & 41962 & 128298 & 83883 \\
\hline $\begin{array}{l}\text { Independent reflections, } \\
R_{\text {int }}\end{array}$ & $5663,0.0429$ & $10961,0.0588$ & $10112,0.0545$ \\
\hline $\begin{array}{l}\text { Data /restraints } \\
\text { /parameters }\end{array}$ & $5663 / 79 / 384$ & $10961 / 1260 / 937$ & $10112 / 1 / 702$ \\
\hline $\begin{array}{l}\text { Final } R 1 \text { values } \\
(I>2 \sigma(I))\end{array}$ & 0.0651 & 0.0675 & 0.0564 \\
\hline Final $R 1$ values (all data) & 0.0763 & 0.0830 & 0.0591 \\
\hline $\begin{array}{l}\text { Final } w R\left(F_{2}\right) \text { values (all } \\
\text { data) }\end{array}$ & 0.1914 & 0.1952 & 0.1631 \\
\hline Goodness-of-fit on $F^{2}$ & 1.032 & 1.027 & 1.062 \\
\hline $\begin{array}{l}\text { Largest difference peak } \\
\text { and hole }\left[\text { e. } \AA^{-3}\right]\end{array}$ & $0.58 /-0.67$ & $0.75 /-0.66$ & $0.39 /-0.42$ \\
\hline CCDC & 2002413 & 2002411 & 2015684 \\
\hline
\end{tabular}

Crystals of $1 \supset$ DETA were grown by slow evaporation of a $2.00 \mathrm{~mL} \mathrm{CHCl} / \mathrm{CH}_{3} \mathrm{OH}$ (4 : 1) solution containing $0.0100 \mathrm{mmol} 1$ and $0.0200 \mathrm{mmol}$ DETA. Crystals of PN3 were grown by slow evaporation of a $2.00 \mathrm{~mL} \mathrm{CHCl}_{3}$ solution containing 0.0100 
mmol PN3. Crystals of in-pS-PN4 were grown by saturated solution crystallization of a $2.00 \mathrm{~mL} \mathrm{CH}_{3} \mathrm{OH}$ solution containing $0.0100 \mathrm{mmol}$ in-pS-PN4.

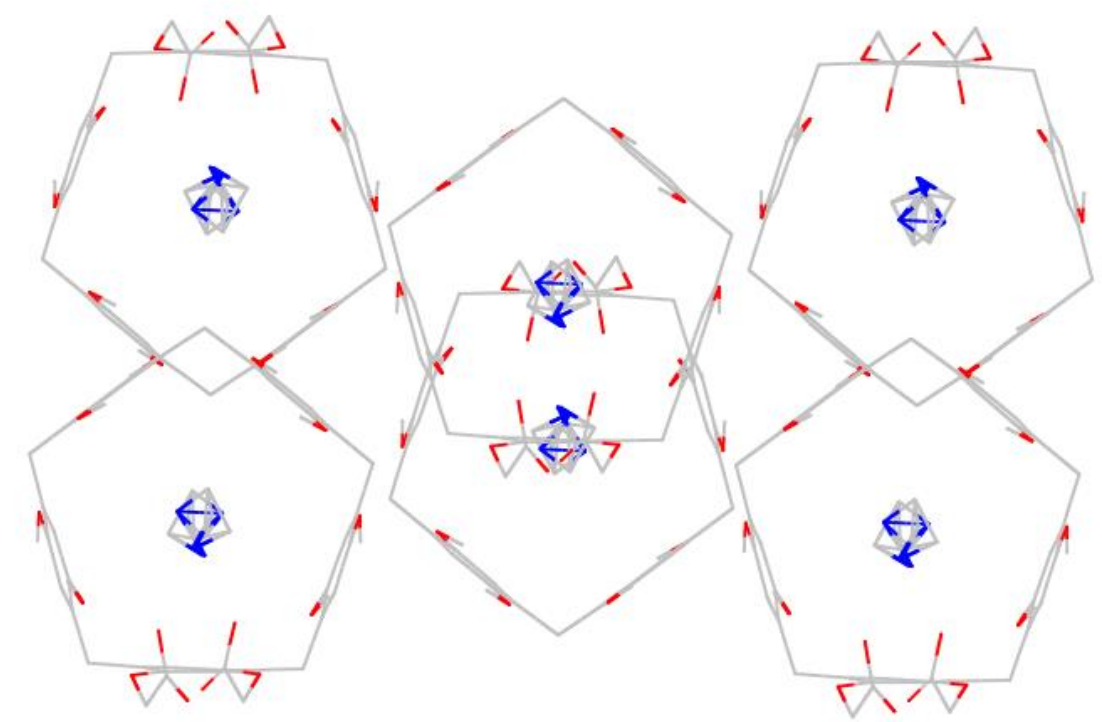

Figure S18. Packing structure of 1دDETA. DETA molecules inside the cavities were disordered. 

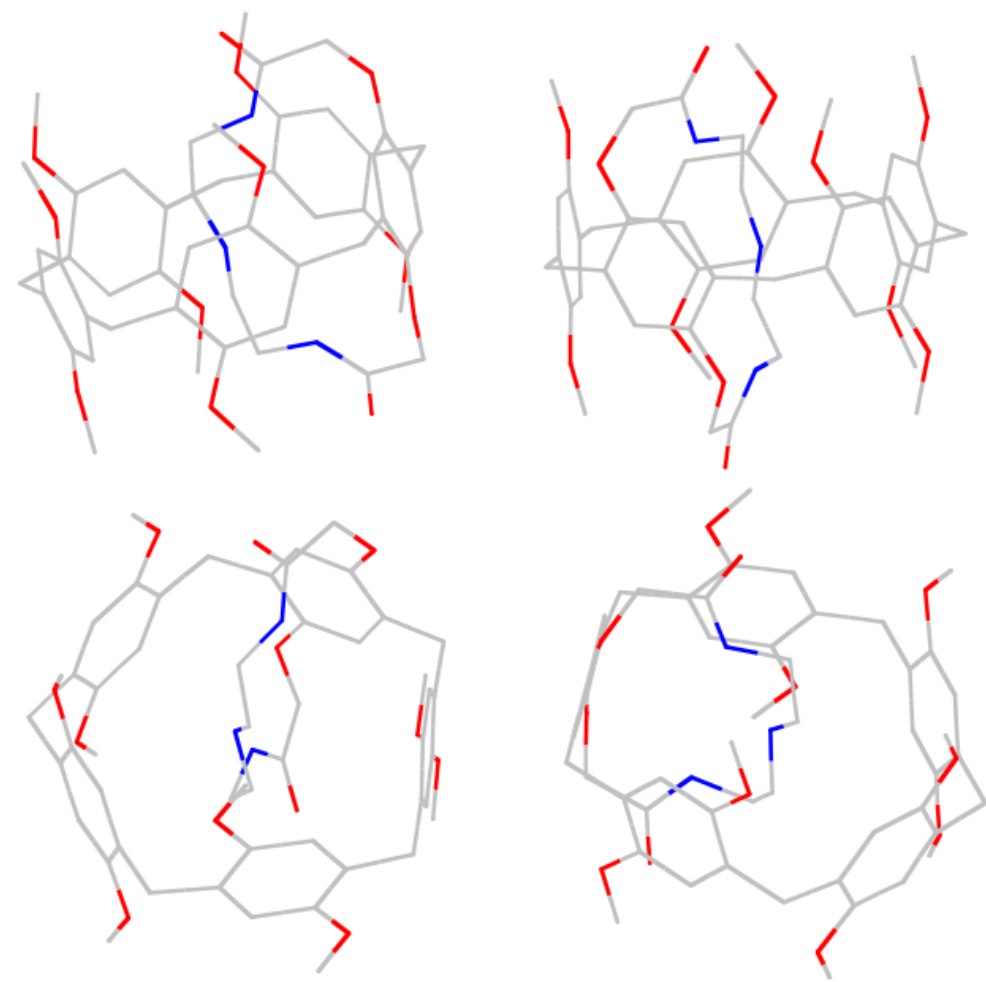

Figure S19. Packing structure of PN3. The in- $p S$ and in- $p R$ conformations were in a 1:1 ratio. Hydrogen atoms and $\mathrm{CHCl}_{3}$ are omitted for clarity.

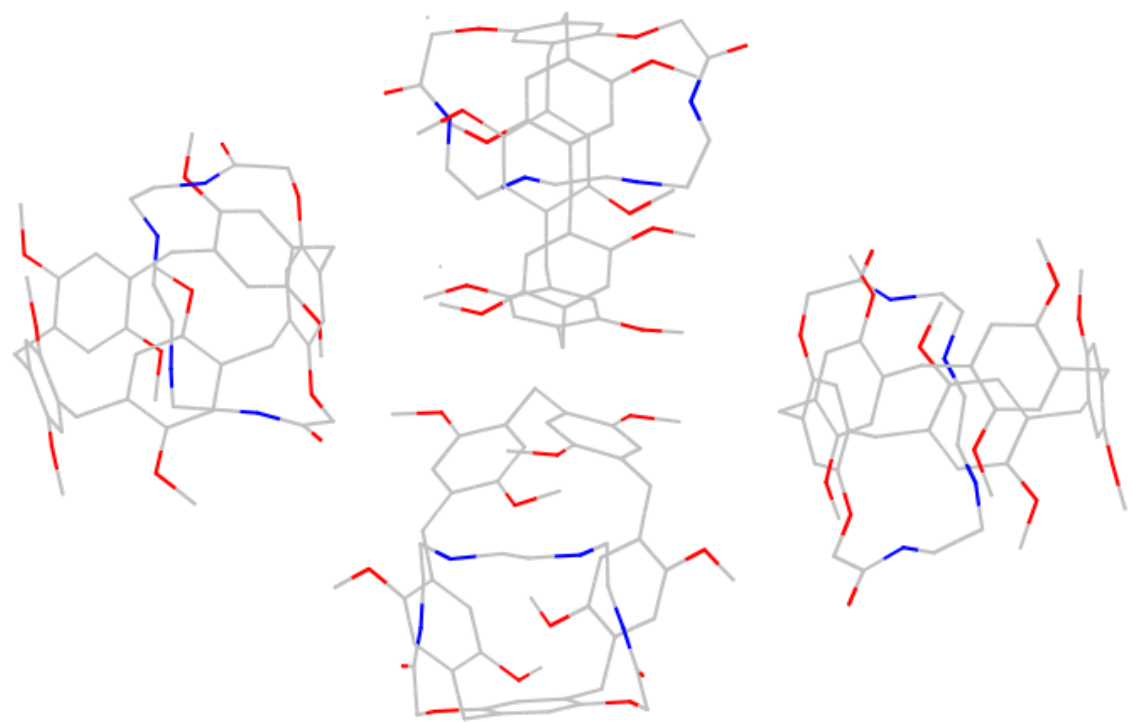

Figure S20. Packing structure of in-pS-PN4. $\mathrm{CH}_{3} \mathrm{OH}$ were omitted. Hydrogen atoms are omitted for clarity. 
5. ${ }^{1} H$ NMR spectra of $\mathbf{P N 3}$ in the presence of acid

(a)

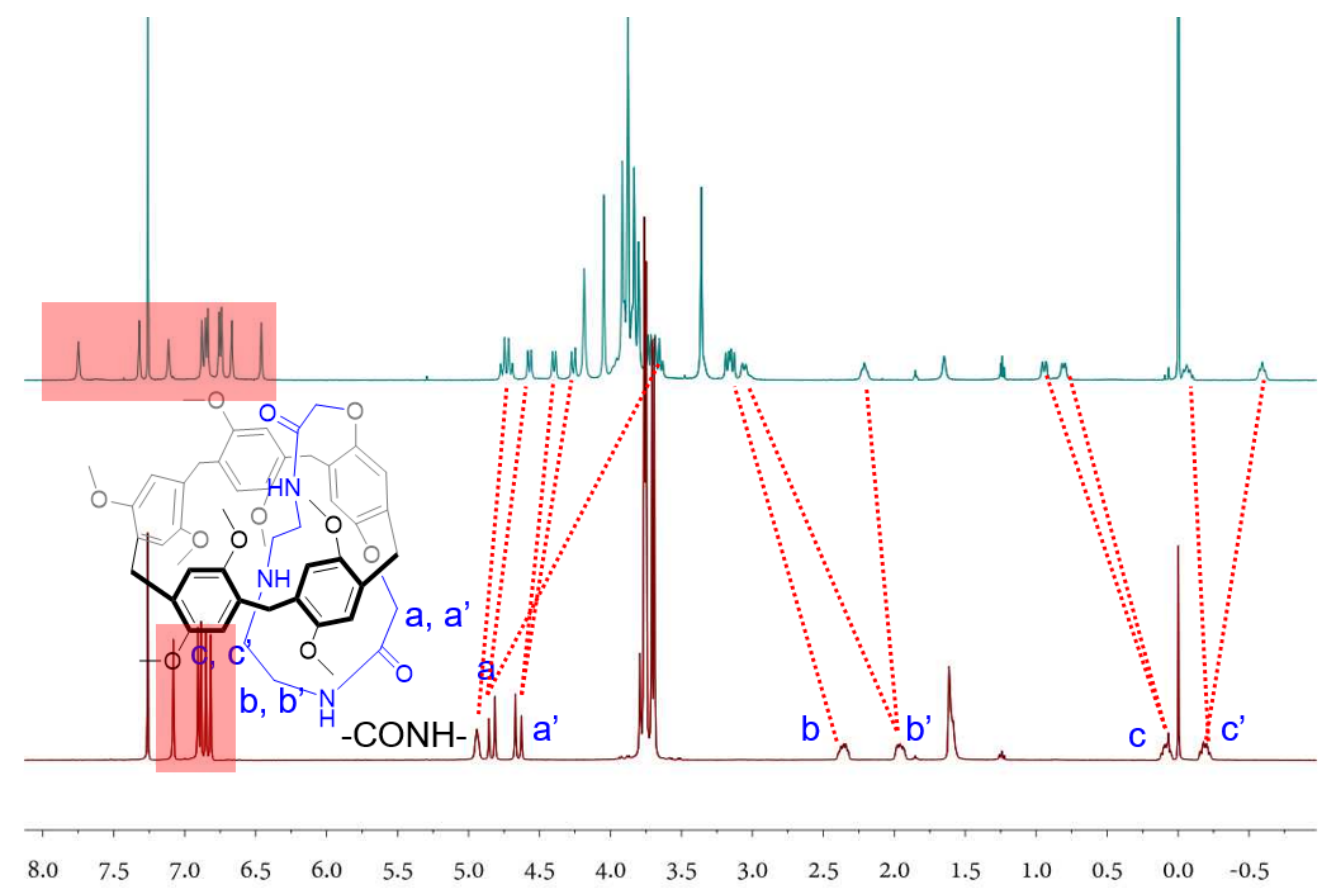

Figure S21. Partial ${ }^{1} \mathrm{H}$ NMR spectra (500 MHz, $\mathrm{CDCl}_{3}, 298 \mathrm{~K}$ ): (a) a solution of 1.00 mM PN3 and $3.00 \mathrm{mM} \mathrm{HCl}$, the protonated PN3 was soluble in $\mathrm{CDCl}_{3}$; (b) PN3.

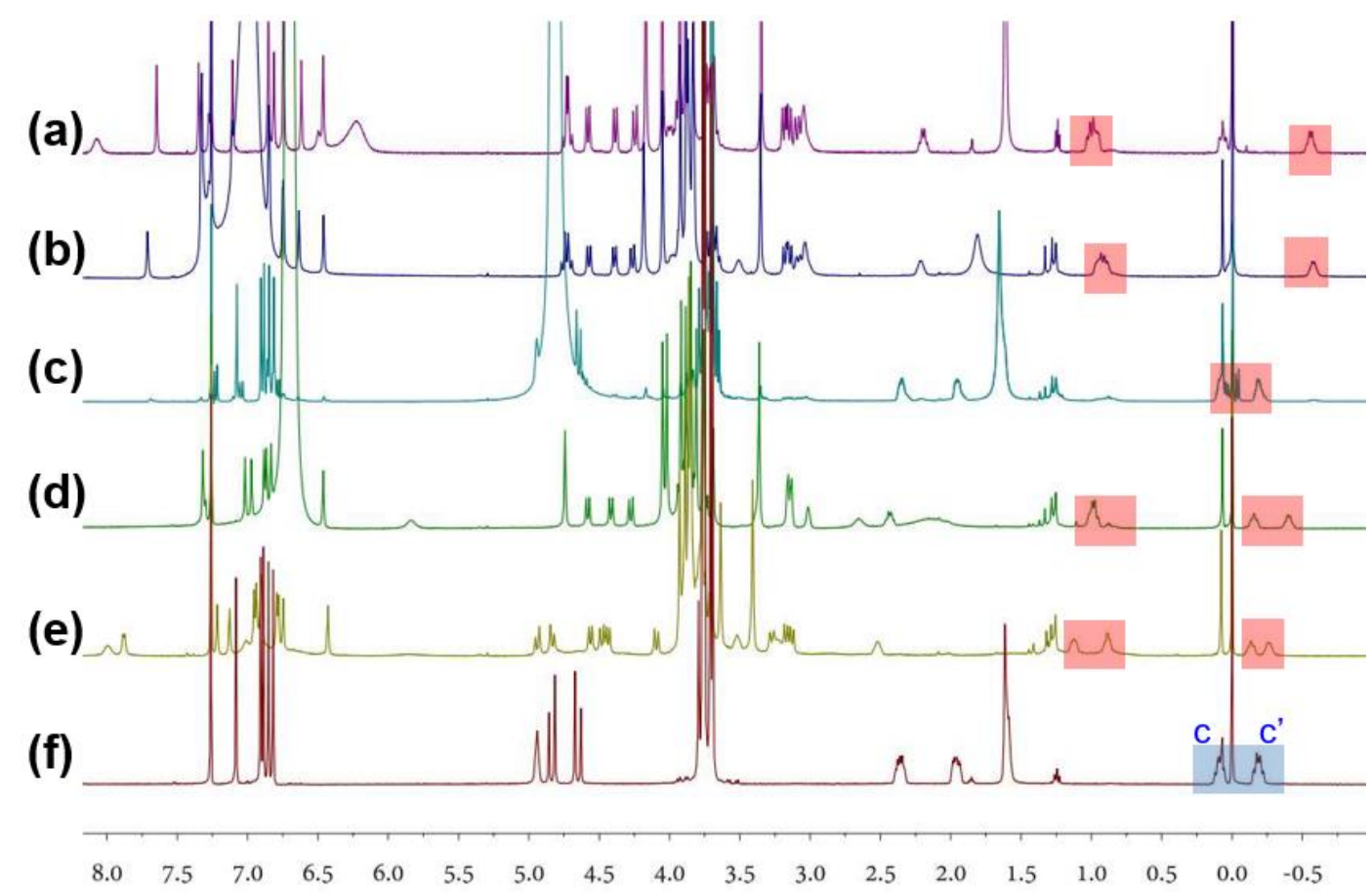

Figure S22. Partial ${ }^{1} \mathrm{H}$ NMR spectra $\left(500 \mathrm{MHz}, \mathrm{CDCl}_{3}: \mathrm{CD}_{3} \mathrm{OD}=1: 1,293 \mathrm{~K}\right):$ (a) a mixture of $1.00 \mathrm{mM}$ PN3 and $3.00 \mathrm{mM} \mathrm{HI}$; (b) a mixture of $1.00 \mathrm{mM}$ PN3 and 3.00 mM HBr; (c) a mixture of $1.00 \mathrm{mM}$ PN3 and $3.00 \mathrm{mM} \mathrm{HPF}_{6}$; (d) a mixture of 1.00 
mM PN3 and $3.00 \mathrm{mM} \mathrm{HBF}_{4}$; (e) a mixture of $1.00 \mathrm{mM}$ PN3 and $3.00 \mathrm{mM}$ TFA; (f) PN3.

6. HPLC resolution of rac-PN4 
(a)

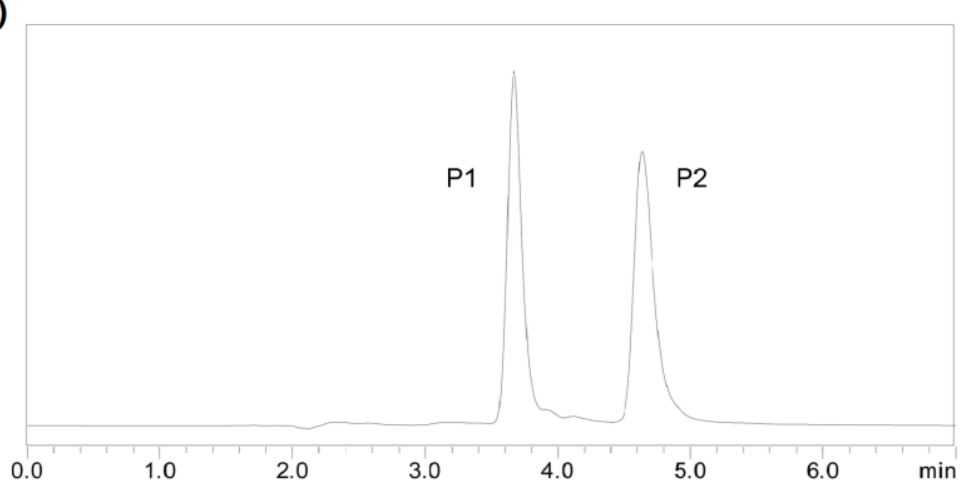

(b)

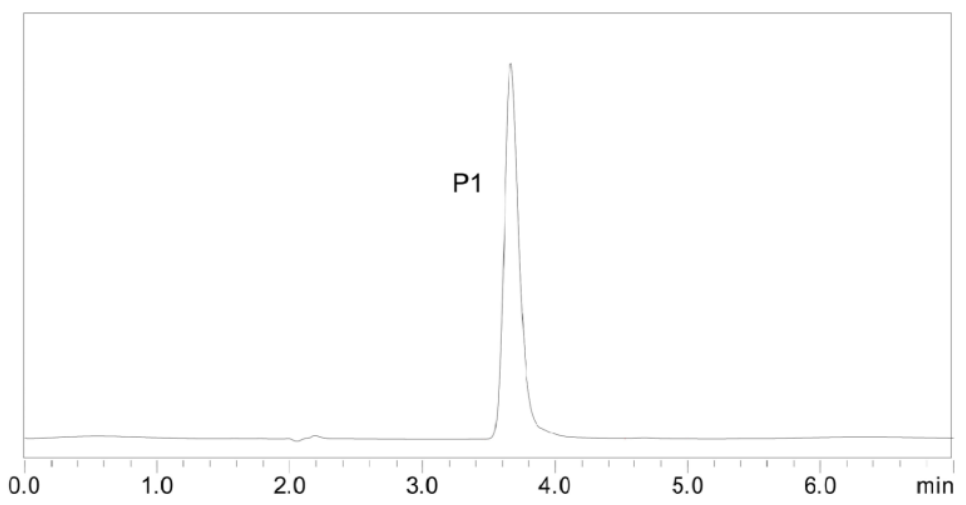

(c)

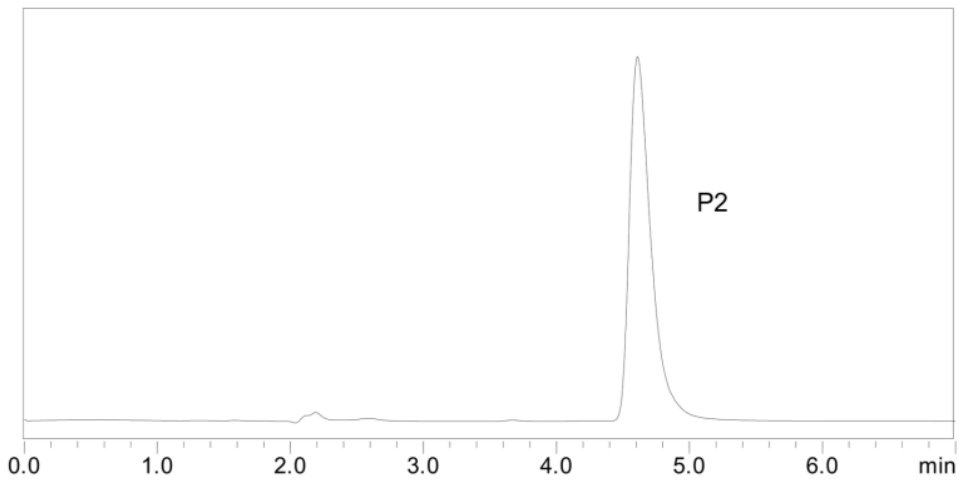

Figure S23. (a) Resolution of the enantiomers peak 1 (P1) and peak 2 (P2) of rac-PN4 by a preparative chiral HPLC $(\mathrm{MeOH} / \mathrm{DCM} / \mathrm{DEA}=70 / 30 / 0.1, v / v / v, 1.0$ $\mathrm{mL} / \mathrm{min}$ ). (b) Chiral HPLC trace (MeOH/DCM/DEA = 70/30/0.1, $v / v / v, 1.0 \mathrm{~mL} / \mathrm{min}$ ) of P1. (c) Chiral HPLC trace (MeOH/DCM/DEA $=70 / 30 / 0.1, v / v / v, 1.0 \mathrm{~mL} / \mathrm{min})$ of P2. 


\section{Quantum chemical calculation of the absolute conformations of P1 and P2}

The absolute conformations of $\mathbf{P 1}$ and $\mathbf{P 2}$ were determined by quantum chemical calculations of their theoretical ECD spectra. In order to avoid uncertainties in ordinary conformational analysis of these macrocyclic molecules, the lowest energy conformer of in-pR-PN4 was constructed by modifying the crystal structure of its homologous compound (CCDC 1016257). This conformer was reoptimized using DFT at the B3LYP/6-31G(d) level using the Gaussian 09 program. ${ }^{\text {S3 }}$ The B3LYP/6-31G(d) harmonic vibrational frequencies were further calculated to confirm its stability (Figure S17). The energies, oscillator strengths, and rotational strengths of the first 60 electronic excitations were calculated using the TDDFT methodology at the M062X/TZVP level in gas phase. The ECD spectra was simulated by the overlapping Gaussian function $(\sigma=0.3 \mathrm{eV},+25 \mathrm{~nm}$ in horizontal axis $),{ }^{\mathrm{S} 4}$ in which velocity rotatory strengths of the first 7 exited states were adopted. The theoretical ECD curve of the enantiomer, in-pS-PN4, was obtained by directly reversing that of in-pR-PN4.

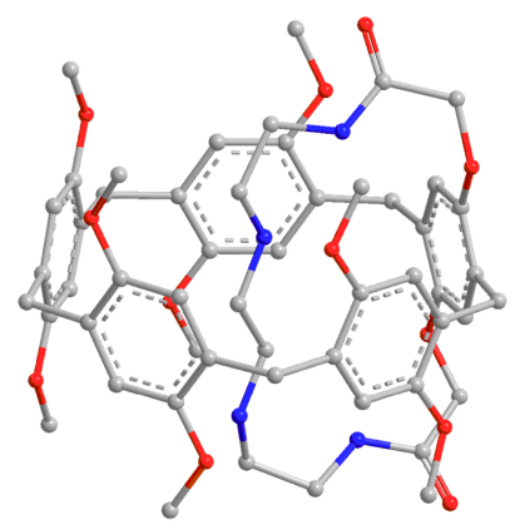

Figure S24. B3LYP/6-31G(d) optimized lowest energy conformer for in-pR-PN4

\begin{tabular}{|c|c|c|c|}
\hline Conf. & $\mathrm{G}($ Hartree $)$ & $\Delta \mathrm{G}(\mathrm{Kcal} / \mathrm{mol})$ & Boltzmann Distribution \\
\hline C1 & -3178.789695 & 0 & 1 \\
\hline
\end{tabular}

Table 1. Energy $(298.15 \mathrm{~K})$ analysis for in-pR-PN4

In the 200-400 nm region (Figure S18), both the experimental ECD curve of P1 and the theoretical one for in- $p R$-PN4 showed positive first, negative second, and positive third Cotton effects, which allowed the assignment of in-pR conformation for $\mathbf{P 1}$. Correspondingly, experimental ECD curve of P2 and the theoretical one for in-pS-PN4 showed the same trends in Cotton effects, which again qualitatively 
allowed the determination of absolute conformation for the enantiomer $\mathbf{P 2}$ as in-pS-PN4.

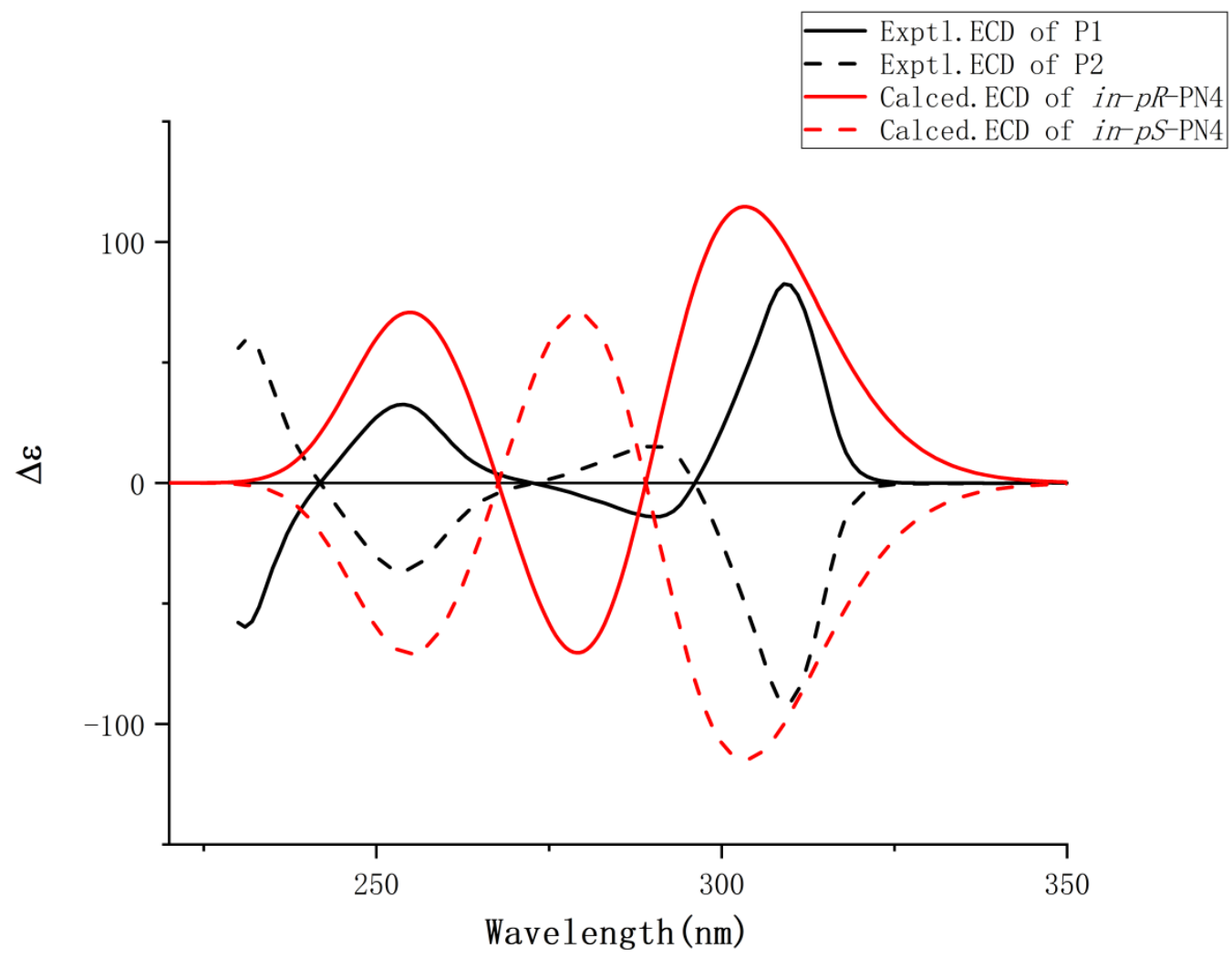

Figure S25. Experimental ECD curves of P1 (solid black line) and P2 (dash black line), and M062X/TZVP//B3LYP/6-31G(d) calculated ECD spectra of in-pR-PN4 (solid red line) and in-pS-PN4 (dash red line).

ECD simulation:

ECD spectrum of each conformation is simulated according to the overlapping Gaussian functions expressed as:

$\Delta \varepsilon(E)=\frac{1}{2.296 \times 10^{-39} \sqrt{\pi} \sigma} \sum_{i}^{\mathrm{A}} \Delta E_{i} \mathrm{R}_{i} e^{\left[-(E-\Delta E i)^{2} / \sigma^{2}\right]}$

where $\sigma$ is half the bandwidth at 1/e peak height and expressed in energy units. The parameters $\Delta E_{i}$ and $R_{i}$ are the excitation energies and rotational strengths for the transition $i$, respectively.

The above function is converted to $\Delta \varepsilon, \lambda$ (wavelength) correlations as: 
$\Delta \varepsilon(\lambda)=\frac{1}{2.296 \times 10^{-39} \sqrt{\pi} \sigma} \sum_{i}^{\mathrm{A}} \Delta E_{i} \mathrm{R}_{i} e^{\left[-(1240 / \lambda-\Delta E i)^{2} / \sigma^{2}\right]}$

and then simulation were accomplished by using the Excel 2003 and the Origin 7.0 software.

Calculated ECD data for in-pR-PN4 in gas phase

\begin{tabular}{|c|c|c|}
\hline \multirow[b]{2}{*}{ State } & \multicolumn{2}{|c|}{ C1 } \\
\hline & $\begin{array}{c}\text { Excitation } \\
\text { energies }(\mathrm{eV})\end{array}$ & $\begin{array}{c}\text { Rotatory } \\
\text { Strengths* }\end{array}$ \\
\hline 1 & 4.5752 & 656.0639 \\
\hline 2 & 4.7064 & -325.4821 \\
\hline 3 & 4.7445 & -197.4108 \\
\hline 4 & 4.8112 & -14.6796 \\
\hline 5 & 4.8398 & -12.0226 \\
\hline 6 & 5.3824 & 166.9925 \\
\hline 7 & 5.4406 & -2.7389 \\
\hline 8 & 5.4678 & -96.1323 \\
\hline 9 & 5.4727 & -17.623 \\
\hline 10 & 5.4801 & -9.4248 \\
\hline 11 & 5.5251 & -7.8836 \\
\hline 12 & 5.5811 & -10.1846 \\
\hline 13 & 5.6144 & -0.1282 \\
\hline 14 & 5.6454 & 0.2066 \\
\hline 15 & 5.6661 & 3.2911 \\
\hline 16 & 5.7451 & -20.4546 \\
\hline 17 & 5.7754 & 55.8353 \\
\hline 18 & 5.8331 & -12.4221 \\
\hline 19 & 5.8729 & 38.2808 \\
\hline 20 & 5.9054 & -51.5368 \\
\hline 21 & 5.9202 & -37.9459 \\
\hline 22 & 5.9362 & -23.3612 \\
\hline 23 & 5.955 & -28.3171 \\
\hline 24 & 5.969 & -9.0445 \\
\hline 25 & 5.9986 & 19.801 \\
\hline 26 & 6.0235 & 37.4572 \\
\hline 27 & 6.0597 & -97.5557 \\
\hline 28 & 6.0792 & -140.7486 \\
\hline 29 & 6.1181 & -367.4741 \\
\hline 30 & 6.1277 & -635.0039 \\
\hline 31 & 6.1568 & -304.6556 \\
\hline 32 & 6.1806 & 161.5377 \\
\hline 33 & 6.1956 & -1423.9137 \\
\hline 34 & 6.2045 & 948.8581 \\
\hline
\end{tabular}




\begin{tabular}{|c|c|c|}
\hline c35 & 6.2331 & 764.7845 \\
\hline 36 & 6.2502 & 151.3488 \\
\hline 37 & 6.2728 & 72.483 \\
\hline 38 & 6.2913 & 36.9568 \\
\hline 39 & 6.2997 & 142.398 \\
\hline 40 & 6.3055 & 311.6568 \\
\hline 41 & 6.3197 & 89.3962 \\
\hline 42 & 6.3315 & 72.0235 \\
\hline 43 & 6.3432 & -17.0865 \\
\hline 44 & 6.3575 & 9.7804 \\
\hline 45 & 6.3694 & 24.8289 \\
\hline 46 & 6.3748 & 35.8972 \\
\hline 47 & 6.3943 & 11.8008 \\
\hline 48 & 6.4134 & -6.5263 \\
\hline 49 & 6.4246 & -54.2306 \\
\hline 50 & 6.4364 & 43.2996 \\
\hline 51 & 6.4427 & -55.4749 \\
\hline 52 & 6.4587 & -91.9667 \\
\hline 53 & 6.4855 & 23.5459 \\
\hline 54 & 6.4945 & 7.416 \\
\hline 55 & 6.5057 & -2.2976 \\
\hline 56 & 6.5319 & -79.616 \\
\hline 57 & 6.5328 & -179.1354 \\
\hline 58 & 6.5368 & -139.8747 \\
\hline 59 & 6.5536 & -66.0839 \\
\hline 60 & 6.5675 & 136.4524 \\
\hline & & \\
\hline
\end{tabular}


8. CD spectra of in-pS-PN4

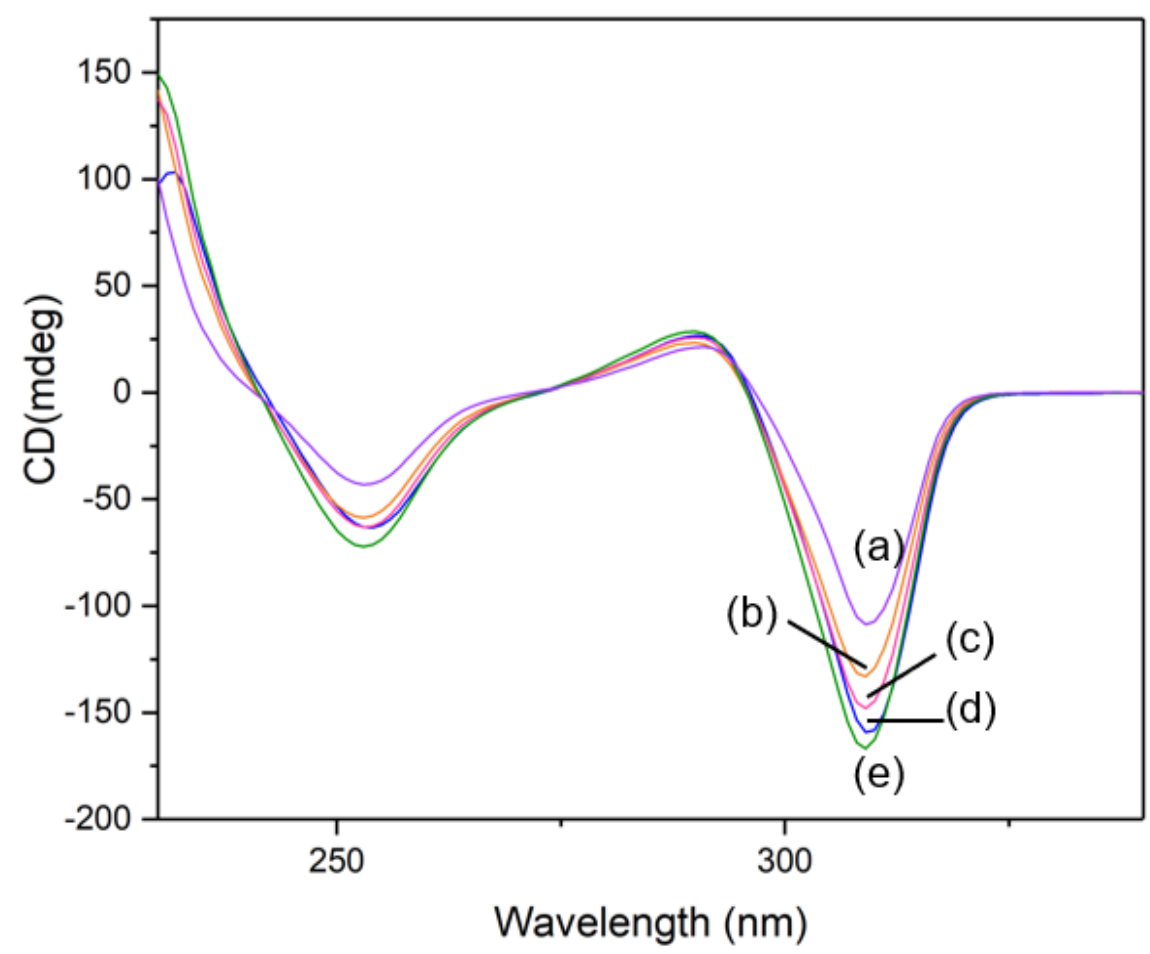

Figure S26. CD spectra of in-pS-PN4 in different kinds of solution: (a) THF; (b) $\mathrm{CHCl}_{3}: \mathrm{EtOH}=1: 1$; (c) $\mathrm{CHCl}_{3}: \mathrm{EtOH}=2: 1$; (d) $\mathrm{CHCl}_{3}$; (e) $\mathrm{CHCl}_{3}: \mathrm{MeOH}=1: 1$. 


\begin{tabular}{|c|c|c|}
\hline & PN3-HCl & PN4-HCl \\
\hline Crystallization Solvent & $\mathrm{CH}_{3} \mathrm{OH}$ & $\mathrm{CH}_{2} \mathrm{Cl}_{2} / \mathrm{H}_{2} \mathrm{O}$ \\
\hline Collection Temperature & $170.0 \mathrm{~K}$ & $170.0 \mathrm{~K}$ \\
\hline Sum Formula & $\mathrm{C}_{51} \mathrm{H}_{60} \mathrm{ClN}_{3} \mathrm{O}_{12}$ & $\mathrm{C}_{55} \mathrm{H}_{82} \mathrm{Cl}_{8} \mathrm{~N}_{4} \mathrm{O}_{17}$ \\
\hline$M r$ & 942.47 & 1354.84 \\
\hline Crystal Size [mm] & $0.19 \times 0.16 \times 0.09$ & $0.28 \times 0.1 \times 0.05$ \\
\hline Crystal System & Monoclinic & Triclinic \\
\hline Space Group & $\mathrm{P} 2{ }_{1} / \mathrm{n}$ & P-1 \\
\hline$a[\AA]$ & $11.8167(9)$ & $11.1358(19)$ \\
\hline$b[\AA]$ & $19.4344(18)$ & $11.7070(19)$ \\
\hline$c[\AA]$ & $20.4342(17)$ & $27.450(5)$ \\
\hline$\alpha\left[^{\circ}\right]$ & 90 & $80.177(5)$ \\
\hline$\beta\left[^{\circ}\right]$ & $95.609(3)$ & $82.927(6)$ \\
\hline$\gamma\left[{ }^{\circ}\right]$ & 90 & $70.428(5)$ \\
\hline$V[\AA 33]$ & $4670.3(7)$ & $3314.0(10)$ \\
\hline$Z$ & 4 & 2 \\
\hline Dcalcd [g cm-3] & 1.340 & 1.358 \\
\hline$\mu[\mathrm{mm}-1]$ & 0.150 & 0.407 \\
\hline $\mathbf{F}(000)$ & 2000.0 & 1424.0 \\
\hline $2 \theta$ range $\left[{ }^{\circ}\right]$ & $4.522-54.47$ & $4.442-49.998$ \\
\hline Reflections collected & 40487 & 34709 \\
\hline Independent reflections, $\boldsymbol{R}_{\text {int }}$ & $10318,0.0828$ & $11599,0.0803$ \\
\hline Data /restraints /parameters & $10318 / 0 / 612$ & $11599 / 16 / 765$ \\
\hline Final $R 1$ values $(I>\mathbf{2 \sigma}(I))$ & 0.0640 & 0.0871 \\
\hline Final $R 1$ values (all data) & 0.0805 & 0.1333 \\
\hline Final $w R\left(F_{2}\right)$ values (all data) & 0.1826 & 0.2486 \\
\hline Goodness-of-fit on $F^{2}$ & 1.082 & 1.028 \\
\hline Largest difference peak and hole $\left[\mathrm{e} . \AA^{-3}\right]$ & $0.69 /-0.66$ & $1.11 /-0.58$ \\
\hline CCDC & 2010931 & 2002412 \\
\hline
\end{tabular}

Crystals of PN3-HCl were grown by saturated solution crystallization of a $2.00 \mathrm{~mL}$ $\mathrm{CH}_{3} \mathrm{OH}$ solution containing $0.0100 \mathrm{mmol} \mathbf{P N 3}$ and $0.0500 \mathrm{mmol} \mathrm{HCl}$. Crystals of PN4-HCl were grown by saturated solution crystallization of a $2.00 \mathrm{~mL} \mathrm{CH}_{2} \mathrm{Cl}_{2}$ solution containing $0.0100 \mathrm{mmol}$ PN4 and $0.0500 \mathrm{mmol} \mathrm{HCl}$ (aqueous solution, 1.00 $\mathrm{mL})$. The crystal was gained from the interface of two phases. 


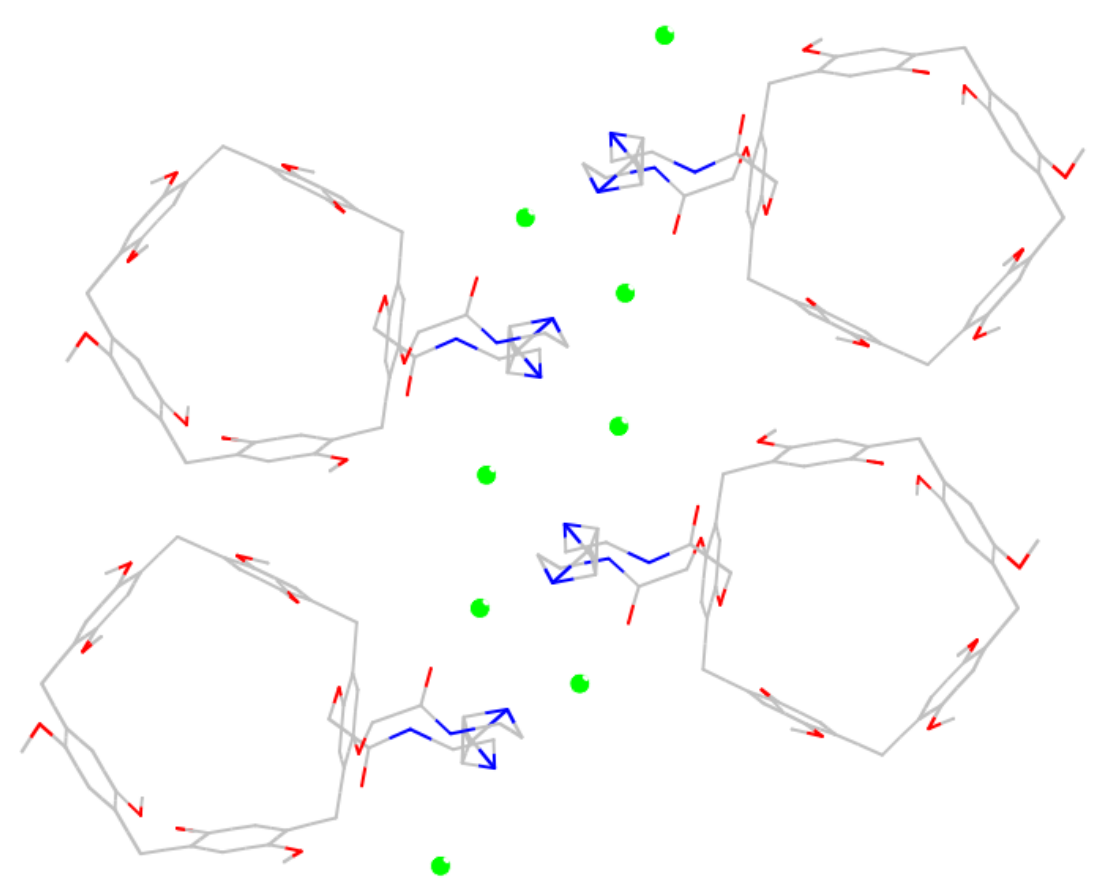

Figure S27. Packing structure of PN4-HCl. $\mathrm{CH}_{2} \mathrm{Cl}_{2}, \mathrm{H}_{2} \mathrm{O}, \mathrm{H}_{3} \mathrm{O}^{+}$and some $\mathrm{Cl}^{-}$anions were omitted. The out-pS and out-pR conformations were in a 1:1 ratio. Hydrogen atoms were omitted for clarity.
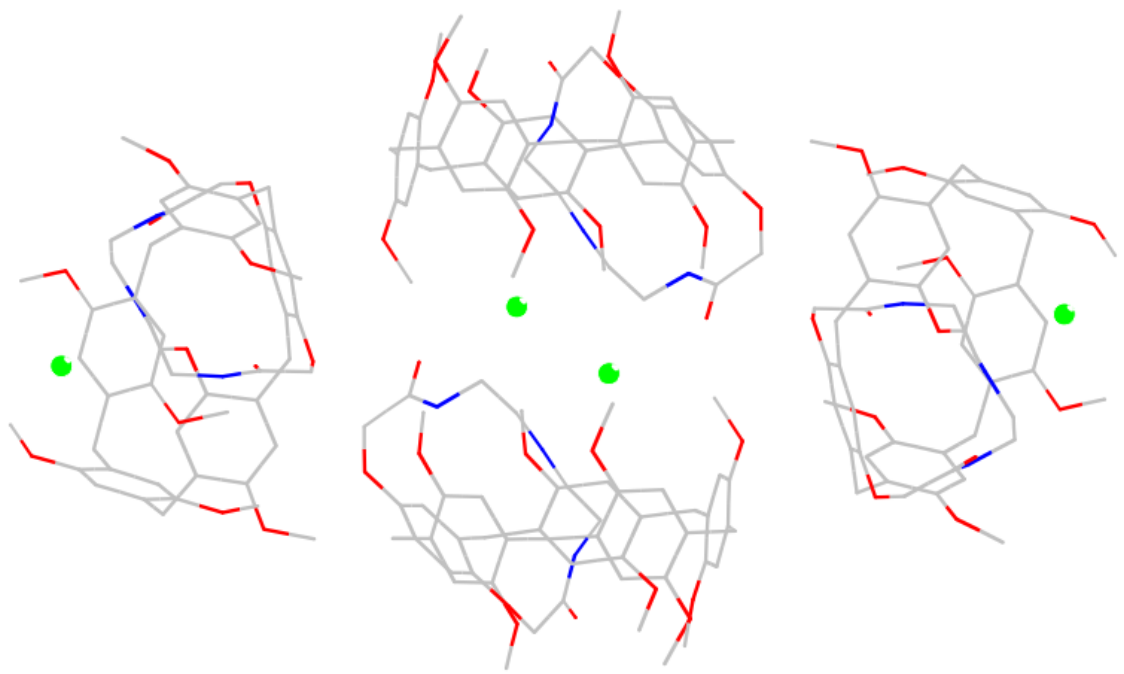

Figure S28. Packing structure of PN3-HCl. Hydrogen atoms were omitted. 
10. ${ }^{1} \mathrm{H} N M R$ and CD spectra of $\mathbf{P N 4}$ in the presence of different acids

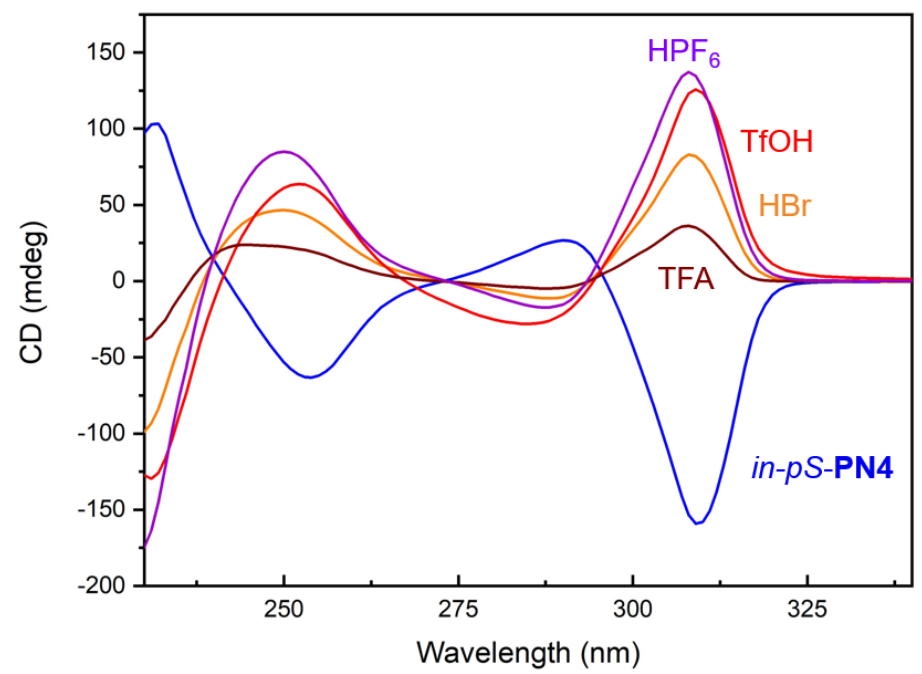

Figure S29. CD spectra of $0.600 \mathrm{mM}$ in-pS-PN4 $\left(\mathrm{CHCl}_{3}: \mathrm{EtOH}=1: 1\right)$ in the presence of different acids (5.0 equiv.).

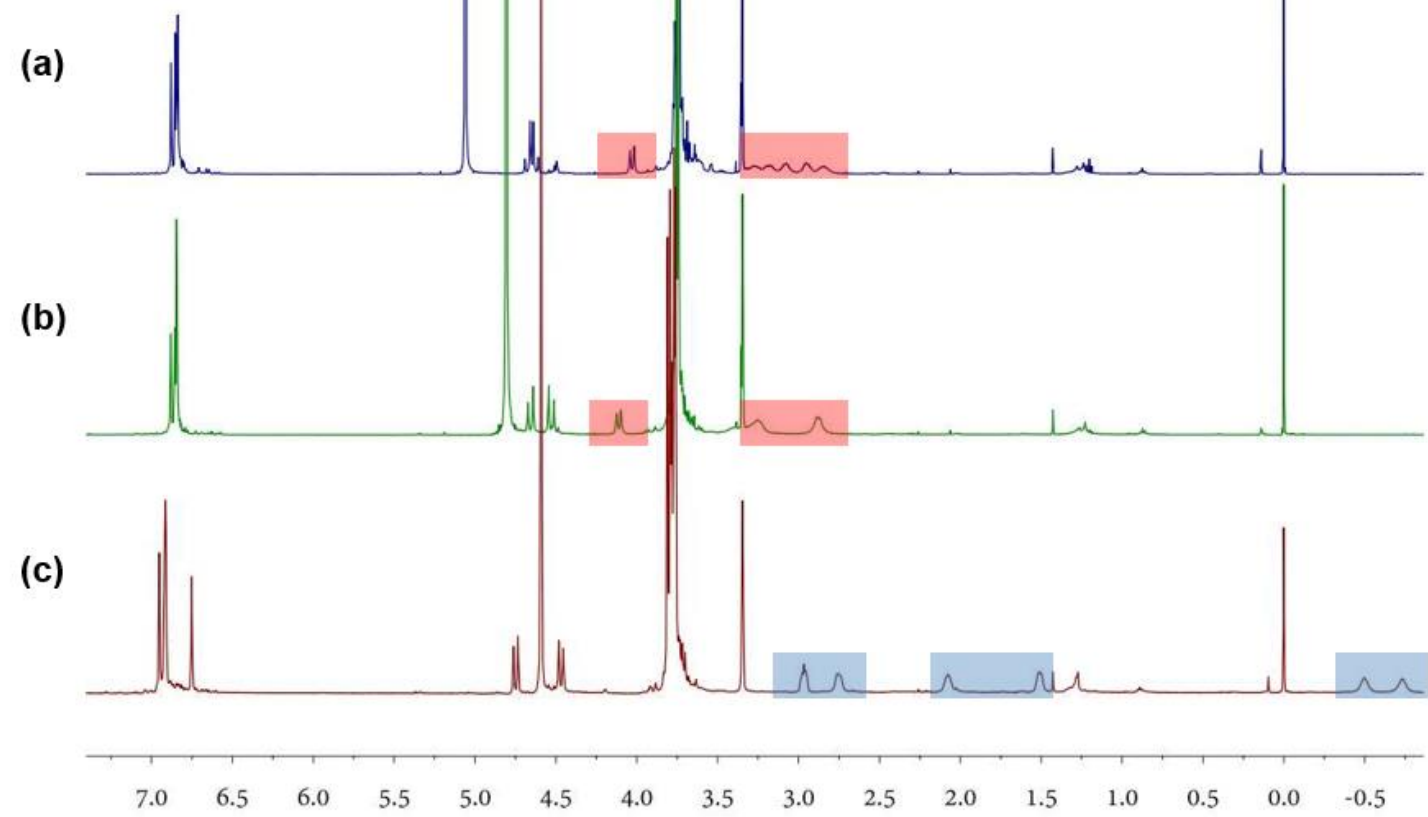

Figure S30. Partial ${ }^{1} \mathrm{H}$ NMR spectra (500 MHz, $\mathrm{CDCl}_{3}: \mathrm{CD}_{3} \mathrm{OD}=1: 1,298 \mathrm{~K}$ ): (a) a mixture of $1.00 \mathrm{mM}$ PN4 and $20.00 \mathrm{mM} \mathrm{TfOH}$; (b) a mixture of $1.00 \mathrm{mM}$ PN4 and $5.00 \mathrm{mM} \mathrm{HBr}$; (c) PN4.

The salts PN4-HPF 6 and PN4-TFA showed poor solubility in the solvent mixture $\left(\mathrm{CDCl}_{3}: \mathrm{CD}_{3} \mathrm{OD}=1: 1\right)$ and proton signals were hard to detect in the NMR spectra. The related studies were investigated by CD. 


\section{References}

S1. Yu, G.; Hua, B.; Han, C., Proton Transfer in Host-Guest Complexation between a Difunctional Pillar[5]arene and Alkyldiamines. Org. Lett. 2014, 16, 2486-2489.

S2. Li, S.-H.; Zhang, H.-Y.; Xu, X.; Liu, Y., Mechanically selflocked chiral gemini-catenanes. Nat. Commun. 2015, 6, 7590.

S3. Gaussian 09, Revision A.1, Frisch, M. J.; Trucks, G. W.; Schlegel, H. B.; Scuseria, G. E.; Robb, M. A.; Cheeseman, J. R.; Scalmani, G.; Barone, V.; Mennucci, B.; Petersson, G. A.; Nakatsuji, H.; Caricato, M.; Li, X.; Hratchian, H. P.; Izmaylov, A. F.; Bloino, J.; Zheng, G.; Sonnenberg, J. L.; Hada, M.; Ehara, M.; Toyota, K.; Fukuda, R.; Hasegawa, J.; Ishida, M.; Nakajima, T.; Honda, Y.; Kitao, O.; Nakai, H.; Vreven, T.; Montgomery, Jr., J. A.; Peralta, J. E.; Ogliaro, F.; Bearpark, M.; Heyd, J. J.; Brothers, E.; Kudin, K. N.; Staroverov, V. N.; Kobayashi, R.; Normand, J.; Raghavachari, K.; Rendell, A.; Burant, J. C.; Iyengar, S. S.; Tomasi, J.; Cossi, M.; Rega, N.; Millam, J. M.; Klene, M.; Knox, J. E.; Cross, J. B.; Bakken, V.; Adamo, C.; Jaramillo, J.; Gomperts, R.; Stratmann, R. E.; Yazyev, O.; Austin, A. J.; Cammi, R.; Pomelli, C.; Ochterski, J. W.; Martin, R. L.; Morokuma, K.; Zakrzewski, V. G.; Voth, G. A.; Salvador, P.; Dannenberg, J. J.; Dapprich, S.; Daniels, A. D.; Farkas, Ö.; Foresman, J. B.; Ortiz, J. V.; Cioslowski, J.; Fox, D. J. Gaussian, Inc., Wallingford CT, 2009.

S4. Stephens, P. J.; Harada, N. ECD cotton effect approximated by the Gaussian curve and other methods. Chirality 2010, 22, 229-233. 